\title{
When image correlation is needed: Unravelling the complex dynamics of a slow-moving landslide in the tropics with dense radar and optical time series
}

\author{
Antoine Dille ${ }^{a, b, *}$, François Kervyn ${ }^{a}$, Alexander L. Handwerger ${ }^{c, d}$, Nicolas d'Oreye e,f, \\ Dominique Derauw $^{\text {e,g,h}}$, Toussaint Mugaruka Bibentyo ${ }^{\mathrm{a}, \mathrm{i}, \mathrm{j}}$, Sergey Samsonov ${ }^{\mathrm{k}}$, \\ Jean-Philippe Malet ${ }^{1}$, Matthieu Kervyn ${ }^{\mathrm{b}}$, Olivier Dewitte ${ }^{\mathrm{a}}$ \\ ${ }^{a}$ Department of Earth Sciences, Royal Museum for Central Africa, Tervuren, Belgium \\ ${ }^{\mathrm{b}}$ Department of Geography, Earth System Science, Vrije Universiteit Brussel, Brussels, Belgium \\ ${ }^{\mathrm{c}}$ Joint Institute for Regional Earth System Science and Engineering, University of California, Los Angeles, CA, USA \\ ${ }^{\mathrm{d}}$ Jet Propulsion Laboratory, California Institute of Technology, Pasadena, CA, USA \\ ${ }^{\mathrm{e}}$ European Centre for Geodynamics and Seismology, Walferdange, Luxembourg \\ ${ }^{\mathrm{f}}$ National Museum of Natural History, Luxembourg, Luxembourg \\ ${ }^{\mathrm{g}}$ Instituto de Investigación en Paleobiología y Geología, Universidad Nacional de Rio Negro - CONICET, Río Negro, Argentina \\ ${ }^{\mathrm{h}}$ Centre Spatial de Liège, Université de Liège, Angleur, Belgium \\ ${ }^{\mathrm{i}}$ Département de Géologie, Université Officielle de Bukavu, Bukavu, DR Congo \\ ${ }^{\mathrm{j}}$ Department of Geology, Ghent University, Ghent, Belgium \\ ${ }^{\mathrm{k}}$ Canada Centre for Mapping and Earth Observation, Natural Resources Canada, Ottawa, Canada \\ ${ }^{1}$ Institut Terre et Environnement de Strasbourg, ITES, CNRS/Université de Strasbourg, Strasbourg, France
}

\section{A R T I C L E I N F O}

\section{Editor: Jing M. Chen}

\section{Keywords:}

Landslide mechanisms and controls

Landslide kinematics

Ground deformation

Pore-water pressure

SAR

Radar-amplitude

UAS

Optical satellite imagery

Tropical Africa

Kivu rift

\begin{abstract}
A B S T R A C T
Slow-moving landslides exhibit persistent but non-uniform motion at low rates which makes them exceptional natural laboratories to study the mechanisms that control the dynamics of unstable hillslopes. Here we leverage $4.5+$ years of satellite-based radar and optical remote sensing data to quantify the kinematics of a slow-moving landslide in the tropical rural environment of the Kivu Rift, with unprecedented high spatial and temporal resolution. We measure landslide motion using sub-pixel image correlation methods and invert these data into dense time series that capture weekly to multi-year changes in landslide kinematics. We cross-validate and compare our satellite-based results with very-high-resolution Unoccupied Aircraft System topographic datasets, and explore how rainfall, simulated pore-water pressure, and nearby earthquakes control the overall landslide behaviour. The landslide exhibited seasonal and multi-year velocity variations that varied across the landslide kinematic units. While rainfall-induced changes in pore-water pressure exerts a primary control on the landslide motion, these alone cannot explain the observed variability in landslide behaviour. We suggest instead that the observed landslide kinematics result from internal landslide dynamics, such as extension, compression, material redistribution, and interactions within and between kinematic units. Our study provides, a rare, detailed overview of the deformation pattern of a landslide located in a tropical environment. In addition, our work highlights the viability of sub-pixel image correlation with long time series of radar-amplitude data to quantify surface deformation in tropical environments where optical data is limited by persistent cloud cover and emphasize the importance of exploiting synergies between multiple types of data to capture the complex kinematic pattern of landslides.
\end{abstract}

\section{Introduction}

Slow-moving ( $\mathrm{mm} \mathrm{year}^{-1}$ to $100 \mathrm{~m} \mathrm{year}^{-1}$ ), deep-seated $(>5 \mathrm{~m}$ ) landslides are common in mountainous landscapes worldwide (Lacroix et al., 2020). Often manifesting as long-term (from months to centuries), persistent slope failures, they can erode hillslopes, dominate the

\footnotetext{
* Corresponding author at: Department of Earth Sciences, Royal Museum for Central Africa, Tervuren, Belgium.

E-mail address: antoine.dille@africamuseum.be (A. Dille).
} 
regional sediment flux, alter the hillslope morphology, and also are natural hazards that cause significant damage to infrastructure (Mackey and Roering, 2011; Froude and Petley, 2018; Lacroix et al., 2020). Slowmoving landslides typically develop in regions with high seasonal rainfall and mechanically weak, clay-rich regolith and rock. Previous work has shown that rainfall-induced changes in pore-water pressure play a primary control on landslide motion (Iverson and Major, 1987; Iverson, 2000; Hilley et al., 2004; Handwerger et al., 2013; Petley et al., 2017; Carey et al., 2019). Most slow-moving landslides therefore exhibit transient velocity variations that track the rainfall patterns, with periods of increased velocity generally corresponding to periods of high rainfall/ snow-melt and pore-water pressure (e.g., Handwerger et al., 2013; Schulz et al., 2017; Cohen-Waeber et al., 2018; Lacroix et al., 2020). Other stress perturbations such as seismic disturbance (Lacroix et al., 2015; Bontemps et al., 2020), undrained loading (Booth et al., 2018) or even atmospheric pressure changes (Schulz et al., 2009a) also influence the landslide kinematics. Most landslides exhibit complex behaviours for reasons that remain elusive (van Asch et al., 2007; Petley et al., 2017; Carey et al., 2019). Examples include delayed kinematic response to stress perturbations, hysteresis in the relationship between rainfall/ pore-water pressure and velocity, non-uniform velocity changes, or a switch in sliding style from slow-motion to rapid surges or even catastrophic failure (Schulz et al., 2009b; Handwerger et al., 2013, 2019b; Carey et al., 2019; Lacroix et al., 2020). Furthermore, external stress perturbations alone do not explain these kinematic changes (Handwerger et al., 2015; Schulz et al., 2017) and landslide motion is further controlled by internal dynamics such as extension, compression, material redistribution, debutressing, rate-induced changes in shear strength of the slope materials properties, etc. (e.g., van Asch et al., 2007; Massey et al., 2013, 2016; Booth et al., 2018). The incomplete understanding of the mechanisms that govern landslide dynamics is a major source of uncertainty that hinders our understanding of their hazardous potential. Therefore it is necessary to continue to investigate slow-moving landslides using state-of-the-art monitoring techniques that capture the complete spatial and temporal landslide behaviours (Lacroix et al., 2020).

High-resolution spatial and temporal observations are needed to unravel these complex landslide dynamics (Delacourt et al., 2007; Stumpf et al., 2014; Hu et al., 2020a; Lacroix et al., 2020). Ground-based measurements (e.g., differential GNSS, strain gauges, borehole inclinometers, etc.) are traditionally used because of high accuracy, precision, and temporal resolution, but access to field sites and cost, place strict limitations on the widespread use of these tools (Booth et al., 2020). Modern remote sensing techniques, such as satellite-based radar or optical imagery, provide measurements of ground surface change with $\mathrm{mm}$ - to cm-scale accuracy and can be used to identify and monitor landslides over much larger areas. The growing availability and quality of short revisit satellite sensors (Elliott et al., 2016, 2020), now enable us to monitor landslides at weekly timescales almost anywhere on earth (Lissak et al., 2020).

The $\mathrm{mm}$ year $^{-1}$ to $100 \mathrm{~m}_{\text {year }}{ }^{-1}$ velocity range exhibited by slowmoving landslides (the latter are sometimes referred to as moderate velocity landsides; Hungr et al., 2014; Lacroix et al., 2020) is well-suited for synthetic aperture radar interferometry (InSAR) and sub-pixel image correlation techniques. InSAR has a millimetre-accuracy with a spatial resolution of meters to tens of meters and can be used to quantify deformation day or night and even when there is significant cloud cover (Scaioni et al., 2014; Wasowski and Bovenga, 2014; Samsonov et al., 2020). Standard InSAR approaches measure the phase change between two data acquisitions to quantify deformation (interferogram). If multiple independent acquisition geometries are available, 2D and 3D ground surface deformation can also be resolved (Hu et al., 2014; Delbridge et al., 2016; Samsonov et al., 2020). To observe changes in surface displacement over time, InSAR measurements are typically combined/inverted into times series (Berardino et al., 2002; Hooper, 2008; Osmanoğlu et al., 2016; Samsonov and D'Oreye, 2017). Many previous studies have used InSAR to investigate landslides, leading to major improvements to our understanding of landslide behaviours (e.g., Hilley et al., 2004; Handwerger et al., 2013, 2015; Wasowski and Bovenga, 2014; Cohen-Waeber et al., 2018). Yet InSAR suffers from limitations related to intrinsic properties of the phase signal. Over time, the signal back-scattered by the surface undergoes decorrelation - e.g., associated with vegetation or moisture changes, deformation rate, surface geometry, etc. - that restricts the use of InSAR to the study of scarcely vegetated landslides consistently slower than $1 \mathrm{~m} \mathrm{yr}^{-1}$ (Singleton et al., 2014; Wasowski and Bovenga, 2014; Schlögel et al., 2015).

When landslide motion is too fast for InSAR, sub-pixel image correlation (also sometimes referred to as offset tracking) can be used to measure landslide deformation (Scaioni et al., 2014; Stumpf et al., 2017; Lissak et al., 2020). Surface displacements are here derived by crosscorrelating two images obtained at different times to measure any offsets between the images (Delacourt et al., 2007; Avouac and Leprince, 2015). Various techniques exist (e.g., statistical, phase correlation), and each generally provides $2 \mathrm{D}$ measurements with an accuracy of $\sim 1 / 10$ th of the pixel size. Recently, authors made use of similar time series inversion approaches to the one applied with InSAR (e.g., Bontemps et al., 2018; Altena et al., 2019; Lacroix et al., 2019a), enhancing temporal sampling and signal-to-noise ratio - that is a comparison of the measured signal to the level of background noise - and overall greatly improving our ability to identify and comprehend time-dependent and transients processes at play. Sub-pixel image correlation has been used to measure large surface displacements of glaciers (Altena et al., 2019; Guo et al., 2020), earthquakes (De Michele et al., 2010; Fielding et al., 2020), or moderate velocity landslides (Delacourt et al., 2004; Raucoules et al., 2013; Stumpf et al., 2017; Bontemps et al., 2018; Lacroix et al., 2019). It can be performed on multiple types of images including SAR, optical, and topographic data. While optical images are most commonly used - amongst other due to availability of medium resolution data going back to decades, these data are typically limited by the presence of cloud cover that can limit the temporal resolution and prevent the identification of transient deformation signals. In those cases, the use of images from active sensors such as SAR amplitude (i.e., a measure of the backscattered SAR signal strength) can be a good alternative (Raucoules et al., 2013; Singleton et al., 2014). Further advantages of using SAR (or radar) amplitude images include a lower sensitivity to vegetation cover and a sensitivity to the vertical component of displacement. Looking similar in many ways to a panchromatic optical image, a SAR-amplitude image differs by its acquisition geometry (side-looking instead of $\sim$ nadir for optical images) that induces geometrical distortions over steep topography (e.g., layover and foreshortening; Dzurisin and Lu, 2006). While the use of SAR-amplitude images is traditionally dominated by case studies on co-seismic and glacier applications, it has been proven a good alternative to study the deformation field of relativity rapid (meters per year) landslides (e.g., Raucoules et al., 2013; Manconi et al., 2014; Milillo et al., 2014; Singleton et al., 2014; Sun and Muller, 2016; Sun et al., 2017; Amitrano et al., 2019; Handwerger et al., 2019a; Li et al., 2019; Xu et al., 2020; Hu et al., 2020b). Yet, so far case studies on landslides are typically limited to the use of a few, or a few dozen of images for which deformation signal is rarely inverted into time series of displacement and images from different orbits seldom combined.

Here, we investigate the mechanisms and controls on the dynamics of a slow-moving deep-seated landslide in the tropical rural environment of the Kivu Rift (DR Congo). We leveraged data from high-revisit radar and optical satellites to quantify landslide motion with very high spatial and temporal resolution between 2015 and 2020. The satellite-derived displacements are validated by direct comparison with each other and very-high-resolution displacement data obtained from successive Unoccupied Aircraft System (UAS) measurements. To unravel the controls on landslide's motion, we examine external forcings such as rainfall-induced changes in pore-water pressure and nearby 
earthquakes. We also apply volume conservation techniques to invert for the subsurface landslide geometry. Our investigation provides a novel and detailed overview of the deformation processes of a landslide sited in a tropical environment - that is largely overlooked in the literature. In particular, we highlight the viability of sub-pixel image correlation with long time series of SAR-amplitude data to quantify surface deformation in tropical environments where optical data is limited by persistent cloud cover and emphasize the importance of combining multiple types of data to capture the complete landslide kinematics.

\subsection{Environmental settings and characteristics of the Ikoma landslide}

Located in the landslide-prone Kivu Rift (Monsieurs et al., 2018; Dille et al., 2019; Depicker et al., 2020; Dewitte et al., 2021), the Ikoma landslide (Fig. $1 ; 2.54^{\circ} \mathrm{S}, 28.73^{\circ} \mathrm{E}$ ) is classified as slow-moving deepseated mass movement (Lacroix et al., 2020). The landslide developed in deeply weathered (up to tens of metres) sequences of late Miocene to Pleistocene basaltic lava (Pasteels et al., 1989; Moeyersons et al., 2004) interbedded with clay-rich layers that host the landslide shear zones (Dille et al., 2019). The landslide is 800-m-long and 400-m-wide and covers an area of $0.17 \mathrm{~km}^{2}$. The topography is sloping towards the southeast, with a steep (average slope angle $\sim 19^{\circ}$ ) upper sector and a gentle downslope section (average slope angle $\sim 6^{\circ}$ ). Estimates from the landslide geometry (ratio between the depth and length of the surface of rupture) give depth ranging from 10 to $50 \mathrm{~m}$ (Dille et al., 2019). The region is characterised by a bimodal annual precipitation regime with an average of $1700 \mathrm{~mm}$, with a wet season from September to May (95\% of yearly rainfall) and a dry season from June to August. Note that the months of January-February are slightly drier months during the wet season. The slope (and its surroundings) is used for subsistence-oriented agriculture and characterised by the presence of many, small agricultural plots (Fig. 1 bc). Multiple crop rotations are typical over a single year, leading to recurrent vegetation changes at the ground surface.

Dille et al. (2019) analysed the mechanisms and failure development of the landslide over a 60-year record. They showed that the slide developed through a series of lateral and retrogressive sliding over the steepest slope section, contributing to the establishment of a step-like surface morphology that indicates rotational movement (Unit I Head). A prominent main scarp with a $\sim 15$ to $35 \mathrm{~m}$ near-vertical wall forms its upper limit. Downslope material accumulation led to the development of an elevated accumulation bulge at the foot of this steepest hillslope section (Fig. 1). Unit I overridden a zone of stationary material located at its foot, which triggered movement of a second unit (Unit II - Central), that is a large, one-block sliding mass undergoing mostly planar movement. This overloading process took place over a decade-long period and the destabilisation of this Central unit occurred after years of material accumulation (Dille et al., 2019). The downslope movement of the Central unit then removed support of the upper sections of its west flank, triggering failure of a third, lateral unit (Unit III). Two recent scarps delimiting back-tilted slope facets here indicate rotational movement (Fig. 1). Interestingly, Dille et al. (2019) highlighted that rather than due to a direct trigger such as rainfall or earthquakes, some phases of instability seem principally caused by the intrinsic evolution of the hillslope associated with weathering-related weakening of the slope strength through time. Their results emphasized the significance of considering interactions between the different dynamic Earth processes, as well as the relative particularity of landslide processes in tropical environments - where weathering is a central geomorphological component (Thomas, 1994; Migon, 2010). The kinematics of the landslide and its controls remain yet to be explored.

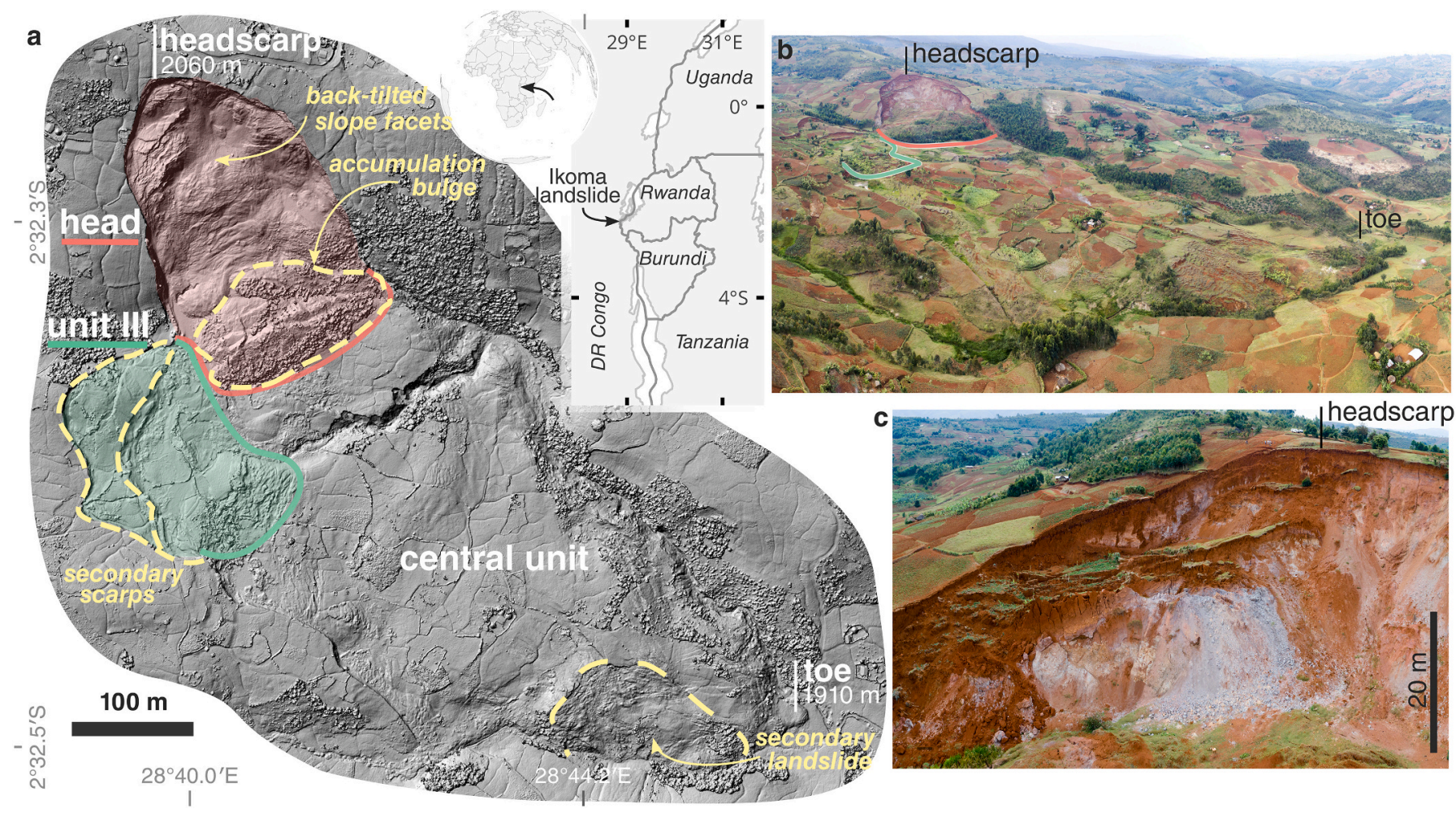

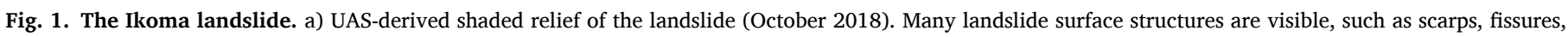

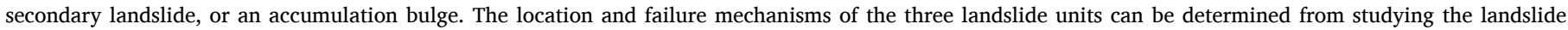

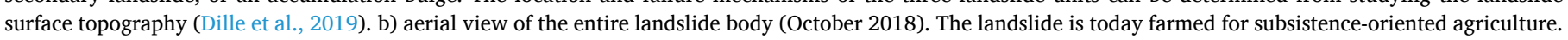

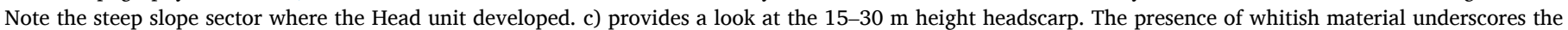
(deep) alteration of the original basalt layers. 


\section{Datasets}

\subsection{Radar satellite images}

We examined 177 descending and 195 ascending high-resolution $(\sim 1.5 \mathrm{~m}$ in range and $\sim 2.0 \mathrm{~m}$ in azimuth) COSMO-SkyMed (CSK) SAR-amplitude images between March 2015 - April 2019 (Fig. 2). There is an average of 8 days between successive images for each orbit. We used the "InSAR automated Mass processing Toolbox for multidimensional Time series" (MasTer) processing chain (Derauw et al., 2020) for i) precise coregistration (correction of shifts between images induced by slight differences in acquisition conditions) of images from each orbit to a 'super reference' image and ii) the geocoding of all amplitude images on a common grid. The super reference image for each series was selected as the image that minimised the perpendicular baseline between all image pairs. The SAR data were geocoded to a 5-m resolution Digital Surface Models (DSM) created from 3 bistatic TanDEM-X pairs from Nov. 2011 and Jan. 2012 (e.g., Albino et al., 2015). We created two different datasets, one with geocoded (i.e., orthorectified) and one with non-geocoded (i.e., in radar geometry) amplitude images; the latter allowing the characterisation of 3D deformation fields. We also tested if we could improve the signal-to-noise ratio in displacement time series by reducing speckle from taking the median of SAR images acquired $<15$ days apart. Prior to taking the median value and image matching, the SAR amplitude images were upsampled from 2 to $1 \mathrm{~m}$ resolution using a bilinear interpolation scheme to reduce mean error in measured displacement (Debella-Gilo and Kääb, 2011) and avoid aliasing in the correlation function (Avouac and Leprince, 2015).

\subsection{Optical satellite images}

We assembled a large collection of high-to-medium-resolution optical satellites imagery covering the landslide area. We ultimately used 27 Sentinel-2, 15 Landsat 8, 16 RapidEye and 34 PlanetScope images that are cloud and shadow-free for the period 2010-2020 (Fig. 2). To avoid complex viewing geometry adjustments, we only used images with the same orbit (path) for each sensor. We also created a very-high-resolution orthomosaic from photogrammetric processing of a Pléiades triplet from July 2018 in MicMac (Rupnik et al., 2017) and had access to another Pléiades image from March 2015. We used the 2018 Pléiades orthomosaic as a reference framework to correct global shifts between images of each given sensor in AROSICS (Scheffler et al., 2017) before calculating local offsets. Prior to image matching, we resampled Pléiades and RapidEye images to $3 \mathrm{~m}$ resolution (i.e., the PlanetScope image resolution) and Landsat 8 pansharpened images to $10 \mathrm{~m}$ resolution (i.e., the Sentinel-2 image resolution) using a bilinear interpolation scheme. This allowed the integration of offset maps from respectively high- (Pléiades, PlanetScope and RapidEye) and medium- (Sentinel-2 and Landsat 8) resolution sensors for the reconstruction of time-series of ground deformation, improving data redundancy and temporal sampling. We used images orthorectified by providers (Planet Team, 2020; Sentinel Sentinel Hub, 2020), and therefore acknowledge potential topographic errors. We, however, postulate that the stacking of large sets of offset maps (see inversion section) should compensate this topographic bias.

\subsection{Unoccupied aircraft systems (UAS)}

As validation dataset, we created three very-high-resolution DSM and orthomosaics by applying structure-from-motion photogrammetry

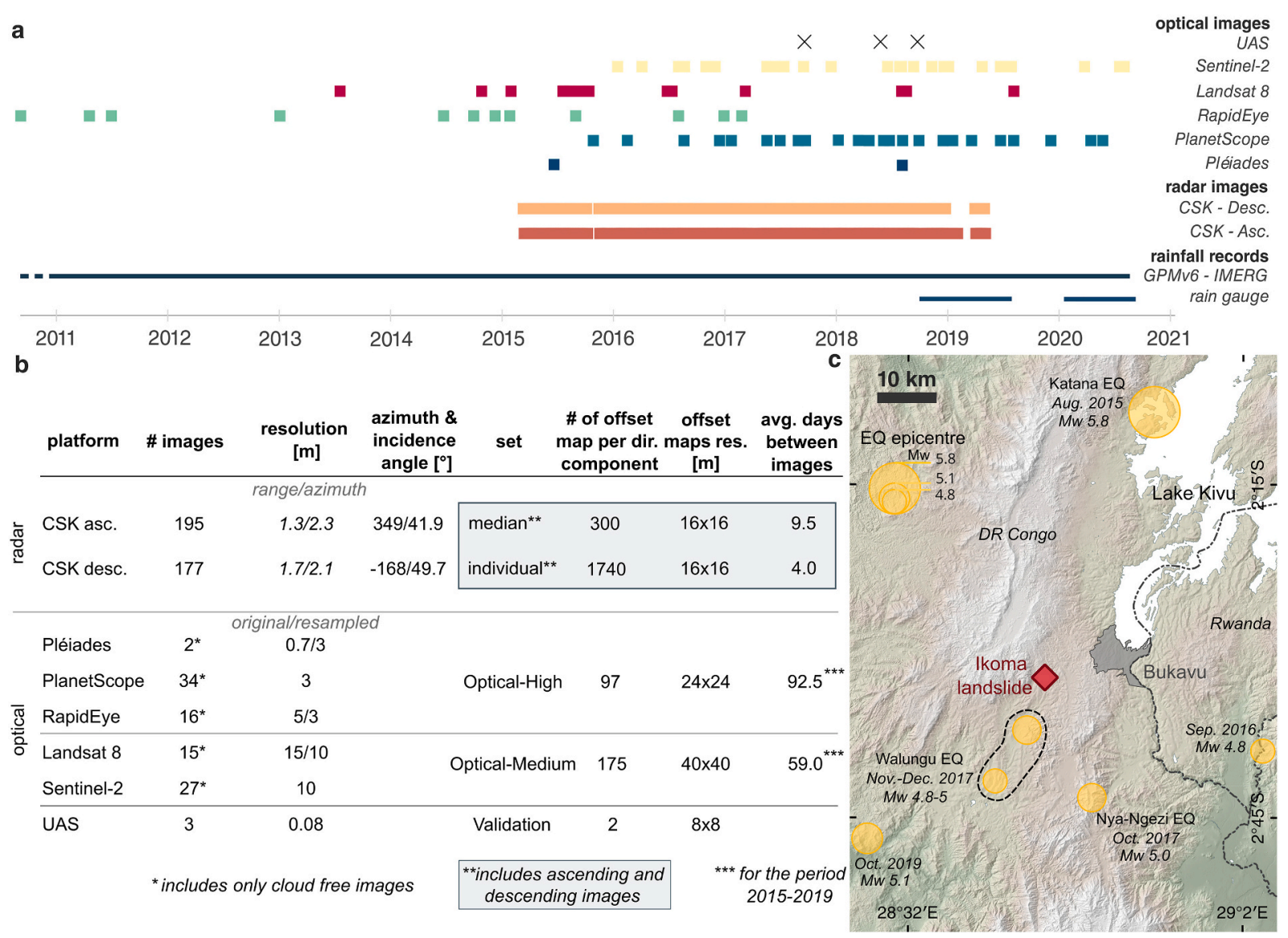

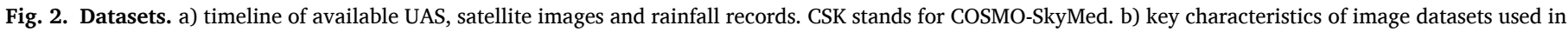
this study. c) location of the main earthquakes documented over the period 2010-2020 close to Ikoma landslide. 
to UAS images acquired over Ikoma landslide in October 2017, June 2018, and October 2018 (Fig. 2). We used a co-alignment workflow in Agisoft Metashape v1.6 (Agisoft, 2020) to reduce registration errors between epochs (e.g., Cook and Dietze, 2019; Hendrickx et al., 2020). Flight paths, flight speed and altitude-to-ground were pre-programmed to minimise motion blur and maintain a uniform $3.9-5 \mathrm{~cm}$ pixel ${ }^{-1}$ ground sampling distance all along the survey area (Supplementary Table 1). Areas of $0.6 \mathrm{~km}^{2}$ (2017) and $0.8 \mathrm{~km}^{2}$ (2018) centred over the $0.17 \mathrm{~km}^{2}$ landslide were surveyed to ensure the presence of stable locations within the output models. For each flight, the position of a series of ground control points was measured using dGNSS and used in the processing workflow (Supplementary Table 1). In addition to nadir views, we acquired sets of oblique $\left(15^{\circ}\right)$ images to reduce systematic DSM errors, (Supplementary Table 1; e.g., James and Robson, 2014). The final DSMs have an $8-10 \mathrm{~cm} \mathrm{pixel}^{-1}$ resolution.

\subsection{Rainfall records and earthquake catalogue}

We used rainfall data from version 6 of the Integrated Multi-satellite Retrievals for Global Precipitation Measurement (IMERG-GPM v6 Final; $0.1^{\circ} \mathrm{x} 0.1^{\circ}$ and half-hourly spatial and temporal resolution; Huffman et al., 2019) for the period 2000-2020. The latter was validated for the region by Monsieurs (2020) and locally from rain-gauge records acquired $<1 \mathrm{~km}$ from the landslide for the period October 2018 - July 2019 and February 2020 - July 2020. Both local and regional validations showed an overall underestimation of the rainfall amount but a good agreement with the temporal pattern. We also examined the earthquake record and selected events significant enough for the potential triggering of hillslope instability over Ikoma based on the Keefer's (Keefer, 2002) relationship between maximum epicentral distances to landslides and earthquake magnitude. For the period 2010-2020, we found six earthquakes with a magnitude $(\mathrm{Mw})$ between 4.8 and 5.8 and an epicentral distance ranging from 9 to $48 \mathrm{~km}$ (Delvaux et al., 2017;
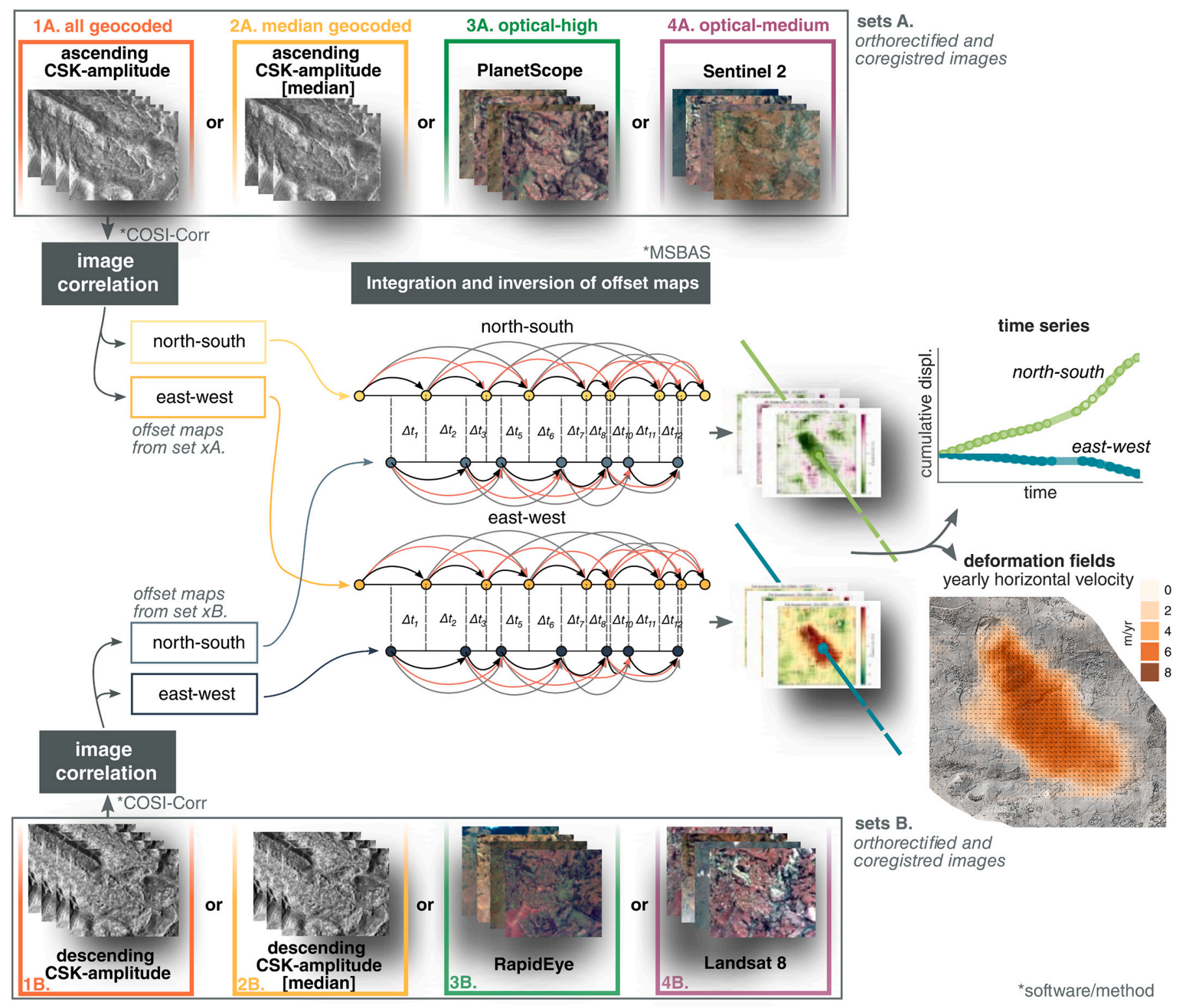

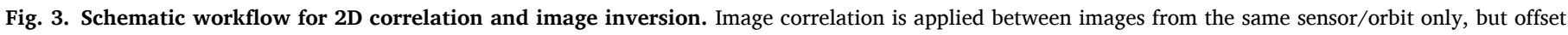

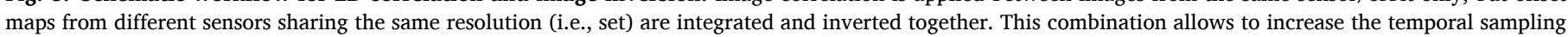

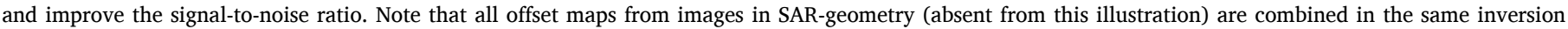
process to produce $3 \mathrm{D}$ datasets. 
Oth et al., 2017; USGS, 2020).

\section{Methods}

Our aim was not to develop new methods or tools but exploit at their maximum the large set of remote sensing data at our disposal to create an extremely dense record of the landslide kinematics - key to unravel controls on landslide deformation and identify potential trends (multiyear, seasonal, episodic). To circumvent challenges imposed by landslide surges, rapidly changing vegetation and the dense tropical cloud cover, SAR-amplitude data forms the core of our methodology. Our workflow is straightforward, uses only well-established methods and can therefore be easily reproduced (Fig. 3).

\section{1. $2 D$ and $3 D$ landslide motion from sub-pixel image correlation}

We performed sub-pixel image correlation in the spatial domain on the orthorectified, co-registered images using COSI-Corr algorithms (Leprince et al., 2007) to obtain measurements of landslide motion for radar, optical and UAS datasets. We independently correlated four different sets of CSK data for ascending and descending orbits. Image sets were formed as follow: i) geocoded, ii) non-geocoded (i.e., radargeometry), iii) individual images, iv) temporal median images (see 2. Dataset). We limited the temporal baseline between correlated pairs to a minimum and maximum of 2.8 and 4.2 months, respectively. This limits i) the computation time, ii) the presence of offset maps with no displacements and iii) decorrelation due to surface changes associated with vegetation and surface motion. The COSI-Corr algorithms work in two iterative steps that allow a refinement of the size windows. The choice of the size of the correlation window results from iterative tests and is a compromise between maximal surface velocity, desired accuracy and required spatial resolution (Delacourt et al., 2007). We here used decreasing window sizes from 128 to 16 pixels for the sub-pixel correlation. We obtained 942 and 798 offsets maps (correlograms) for ascending and descending sets (Fig. 2b). For sets where we took the median of successive amplitude images to reduce speckle, we obtained 152 and 148 offset maps for ascending and descending sets, respectively. We did not apply spatial or temporal filtering to any part of the processing workflow. Although we selected a super reference image to minimise the perpendicular baseline during the coregistration process (see 2. Dataset), we did not set perpendicular baseline threshold. We assume that the stacking of very large sets of offset maps (see inversion section) obtained with different values of perpendicular baseline should compensate the possible topographic bias (e.g., Raucoules et al., 2013). Note that while the correlation of geocoded radar images provides estimations of EW and NS components of displacement, the correlation of non-geocoded images (i.e., in radar geometry) offers estimations of range (or Line-Of-Sight) and azimuth (or along flight) components, which enables the estimation of the full three-dimensional (3-D) surface motion when images from at least two different orbits are present (Milillo et al., 2014; Singleton et al., 2014). After correlation, offset maps in radar geometry were geocoded so that a pixel from ascending and descending orbits represent the same location on the ground.

We applied sub-pixel image correlation to the sets of orthorectified optical satellite images, independently for each sensor. We correlated all images with temporal baselines between 6- and 15-months. We used decreasing windows sizes (from 128 to 8 pixels) to measure the eastwest (EW) and north-south (NS) components of the surface displacement.

The spatial resolution of the offset maps depends on the input image resolution and the size of the sliding correlation windows. Our radar offset maps have a $16 \times 16 \mathrm{~m}$ ground resolution, our high-resolution optical satellite data (Pléiades, PlanetScope and RapidEye) have a 24 $\times 24 \mathrm{~m}$ resolution, and our medium-resolution optical satellite data (Sentinel-2 and Landsat 8) have a $40 \times 40 \mathrm{~m}$ resolution (Fig. 2).

Finally, we created a validation set by correlating $8-10 \mathrm{~cm}$ resolution shaded relief maps from UAS-derived topographic data (October 2017 June 2018 - October 2018). The use of shaded relief commonly offers higher accuracy results than the correlation of orthomosaics (Turner et al., 2015; Clapuyt et al., 2017). We used decreasing windows sizes (from 128 to 16 pixels) to measure the east-west (EW) and north-south (NS) components of the surface displacement. Because of drastic changes over the landslide head related to retrogressive sliding, we additionally had to use displacement information from manual tracking of 40 targets within the landslide head (e.g., Dewitte et al., 2008; Alberti et al., 2020). Vertical displacements were measured from DSMs subtraction.

\subsection{Displacement time series inversions}

To improve temporal coverage and resolution as well as take advantage of data redundancy to improve signal-to-noise ratio, we stacked offset maps to retrieve deformation time series via a Singular Value Decomposition-based inversion (Fig. 3). This is the standard approach used in InSAR time series (e.g., Berardino et al., 2002; Hooper, 2008; Samsonov and d'Oreye, 2017) and since offset maps from subpixel image correlation contain the same information as an unwrapped differential interferogram (i.e., information over the ground displacement in a certain geometry; Singleton et al., 2014) it is appropriate to apply this method. We used a multitemporal SAR interferometric inversion method (the 'Multidimensional Small Baseline Subsets method', MSBAS; Samsonov and d'Oreye, 2012, 2017) to stack the offset maps and invert displacement changes over time. Note that we stacked together EW offset maps and NS offset maps obtained from ascending and descending orthorectified radar datasets (Fig. 2b). For offset maps derived from orthorectified/geocoded sets, we obtained estimates of EW and NS horizontal surface displacements. For offset maps derived from radar-geometry sets (i.e., measuring range and azimuth surface offsets), we obtained estimates of the three-dimensional (3-D) surface displacements. We applied a similar strategy for optical data, here stacking together EW offset maps and NS offset maps obtained from the correlation of high-resolution optical images (Pléiades, PlanetScope and RapidEye, later referred as Optical-High set) and medium-resolution optical images (Sentinel-2 and Landsat 8, later referred to as OpticalMedium set; Figs. 2, 3).

We extracted displacement time series over four different sites within the landslide to constrain deformation patterns. These sites are representative of the movement over the different zones of the landslide (Head, Central unit, Toe and Unit III) and chosen to examine interactions between individual landslide units. Average displacements and standard deviations are measured over $2 \times 2$ pixels regions (Samsonov and D'Oreye, 2017). Note that the rapid motion and large deformation of the upper headscarp caused decorrelation that prevented our time series analyses in this area. We quantified uncertainties in the displacement time series by comparing them to UAS-measured motion for the periods October 2017 - June 2018 and June 2018 - October 2018. Changes in landslide motion were compared to earthquake catalogues and rainfall-induced changes in pore-water pressure, that, in absence of in-situ measurements, were simulated through a homogenous 1D diffusion model fed by rainfall data (Handwerger et al., 2013, 2019b). The pore-water pressure diffusion model also requires information about the landslide thickness and the landslide diffusivity. To solve for diffusivity, we set the landslide thickness to $25 \mathrm{~m}$, which is an average depth value over the landslide (Dille et al., 2019) and a best fit soil diffusivity of $5.0 \times 10^{-5} \mathrm{~m}^{2} \mathrm{~s}^{-1}$. We solved to best fit the value for landslide diffusivity by minimizing the Root Mean Square Error (RMSE) misfit between normalised simulated pore-water pressure and normalised average velocity time series over the landslide (Handwerger et al., 2019b). This diffusivity value falls within the range of diffusivities measured for landslides in weathered basalts (Baum et al., 1998). The pore pressure model was run to steady-state by adding 15 years of IMERG-GPM rainfall estimates (2000-2015; Huffman et al., 2019) 
before the period of the present study. Considering the absence of in-situ measurements and the simple approach applied, we used this pore-water pressure solution for the entire landslide. Also, since our aim is exploring timing and changes in relative magnitude of the pore-pressure over time, only normalised pore-pressure values are compared to landslide velocity. Limits of this approach are e.g., described by Handwerger et al. (2013, 2019).

\subsection{Estimating surface strain and landslide depth}

We estimated landslide depth and surface strain based on UAS-based measurements of landslide motion (2017-2018). We used a plane-strain mass continuity equation considering a range of deformation pixels for computing strain rates (Handwerger et al., 2019b). Since the strain rate tensor measurements are sensitive to noise, we downsampled velocity fields to $10 \times 10 \mathrm{~m}$ resolution. $3 \mathrm{D}$ displacement can be used to quantitatively infer the landslide basal slip surface geometry, and therefore infer the landslide depth (Booth et al., 2013, 2020; Delbridge et al., 2016). Assuming that the horizontal landslide surface velocity is equal to the depth-averaged velocity, we estimated the active landslide depth by performing a thickness inversion based on the measured surface velocity and conservation of volume (Booth et al., 2013, 2020). In summary, the inferred landslide thickness values represent a best solution that does not violate conservation of volume.

\section{Results}

UAS-based measurements provided three looks at the landslide throughout a complete seasonal cycle (September/October is the start of the wet period (measurements $1 \& 3$ ) and June its end (measurement 2 )). The 2017-2018 period is also particularly well-suited to study the landslide mechanisms because it spans one major head retrogression episode (Fig. 4). UAS-measured landslide motion highlights the high spatial variability of velocity fields, confirming the presence of three
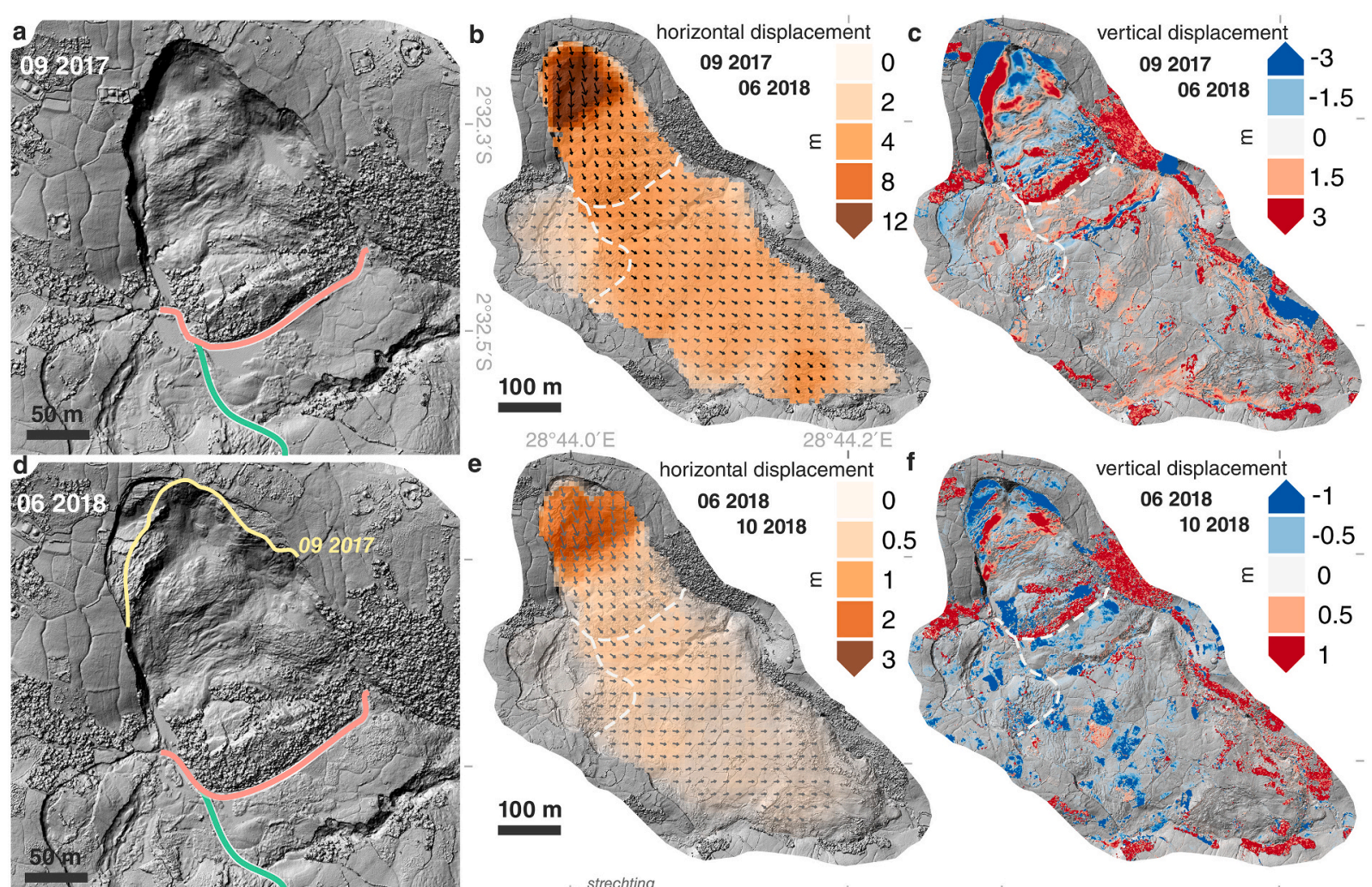

102018
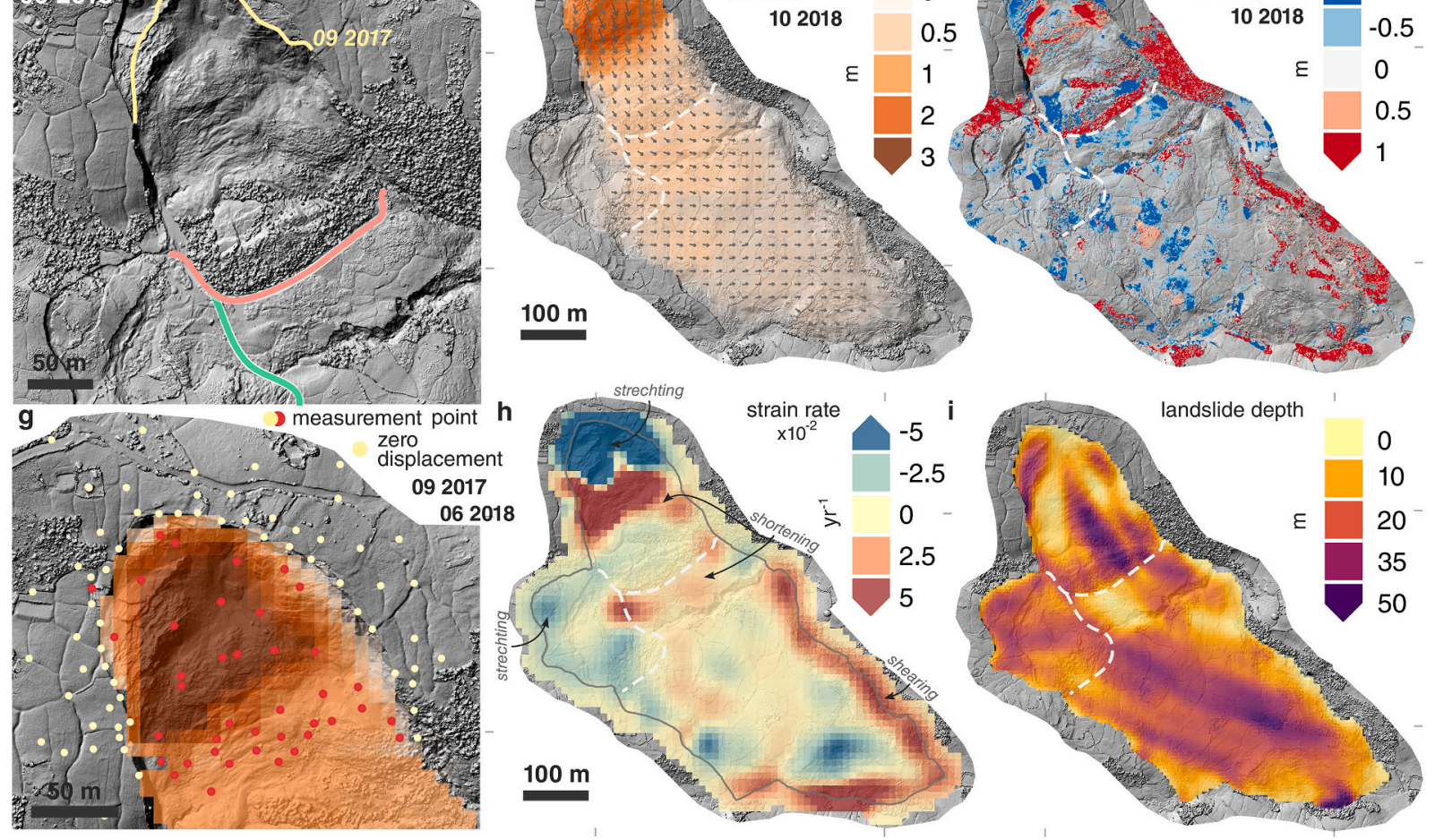

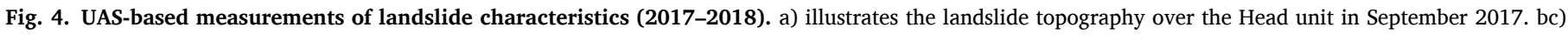

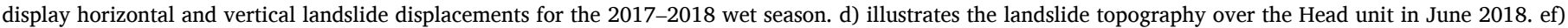

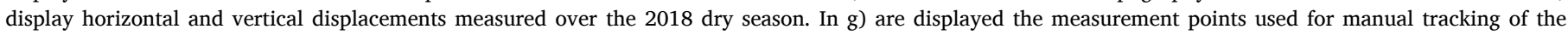

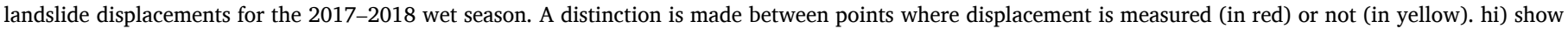
strain rates and depth estimates calculated from 3D displacements over the 2017-2018 period. 
well-defined kinematic units - i.e., portions of the landslide that move coherently - and their distinct movement styles (Fig. 4; Dille et al., 2019). Average and maximal horizontal velocities were 7.2 and $25.0 \mathrm{~m}$ $\mathrm{yr}^{-1}$ over the landslide Head, 3.6 and $4.7 \mathrm{~m} \mathrm{yr}^{-1}$ over the Central unit and 2.0 and $2.8 \mathrm{~m} \mathrm{yr}^{-1}$ over the third, lateral unit (dominated by eastward motion). Vertical displacement maps are dominated by the signal at the landslide Head (up to $5 \mathrm{~m}$ of downward motion). We find stretching in the Head zone and the head of Unit III, shearing along the lateral margins of the landslide body, and shortening at the base of the head unit and Unit III (Fig. 4 h). Landslide depth was estimated by inverting the volume conservation equation from the 3-D surface deformation field. Estimated thickness varies from 5 to $50 \mathrm{~m}$, with a maximum below the landslide headscarp and the lower reach of the Central unit (Fig. 4i).

Our time series inversion of displacements derived from sub-pixel image correlation of SAR-amplitude images allowed us to resolve 4.5 years of landslide motion (Fig. 5). Surface velocity fields from SAR (Fig. 5 abc) showed similarities with UAS-based measurements, except over the upper landslide head - a zone where the ground surface texture changed dramatically alongside the retrogression episodes. We observed distinct kinematic units despite the lower spatial resolution compared to UAS, and low amounts of noise outside the landslide (principally
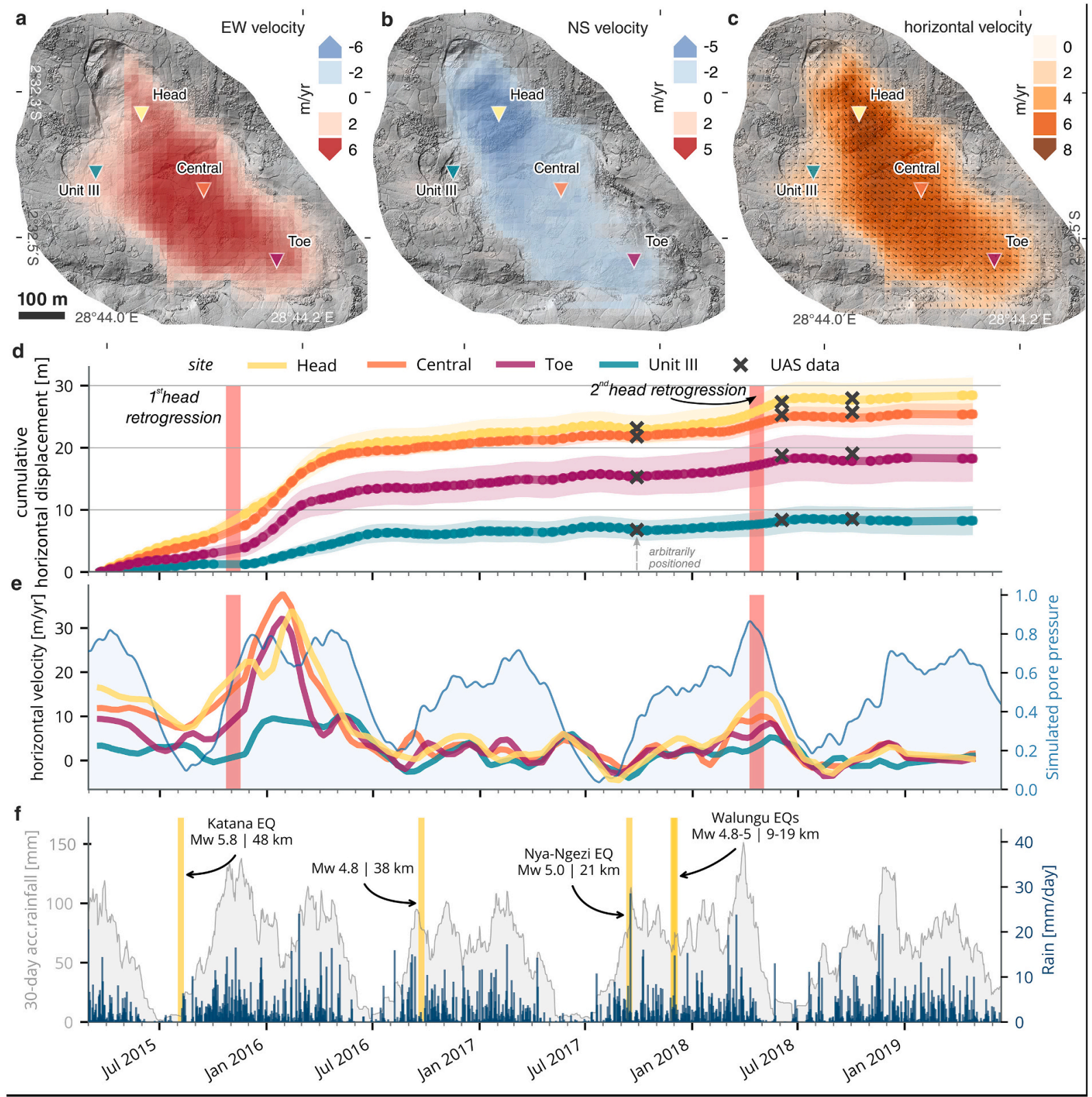

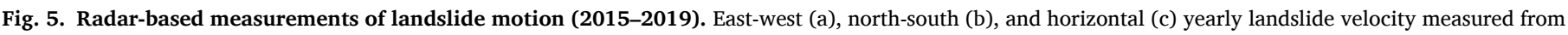

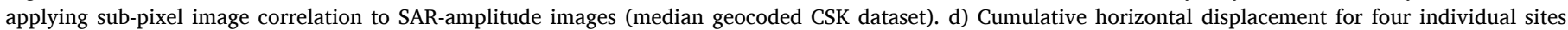

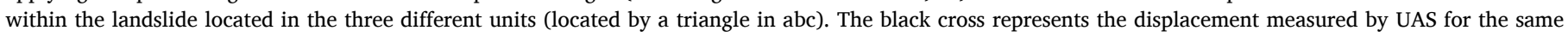

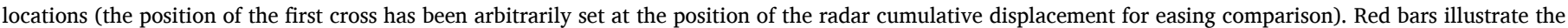

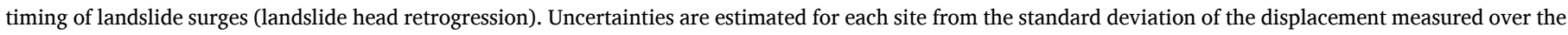

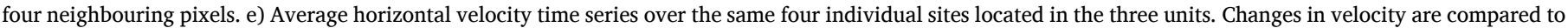

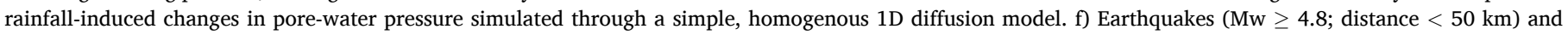

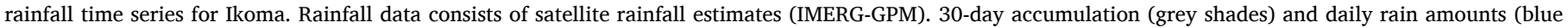
bars) are represented. 
restricted to forested areas). Between March 2015 and May 2019, we measured average and maximal horizontal velocities of 4.6 and $7.0 \mathrm{~m}$ $\mathrm{yr}^{-1}$ over the entire landslide Head unit, 5.0 and $6.8 \mathrm{~m} \mathrm{yr}^{-1}$ over the Central unit and 2.4 and $4.2 \mathrm{~m} \mathrm{yr}^{-1}$ over the third, lateral unit. We also analysed time series of displacement at four different sites (Fig. 5). Up to $30 \mathrm{~m}$ of horizontal displacement was measured from geocoded SARamplitude over the 4.5-year period (Fig. 5d). $23 \mathrm{~m}$ of 3D displacement was measured using amplitude images in radar-geometry (Supplementary Fig. 1). An average displacement difference of $-0.5 \pm 0.5 \mathrm{~m}$ is measured between SAR-amplitude and UAS-based measurements for the four sites and the periods October 2017-June 2018-October 2018.

When combining ascending and descending sets there was an average time separation of 4 days between successive radar acquisitions, making it possible to observe changes in kinematics over weekly timescales. The time series captured complex kinematic changes including seasonal variations, brief and episodic accelerations episodes, and multiyear trends. Seasonal velocity changes are well defined, with consistently higher velocity observed during the wet season (Fig. 5e). For all three landslide units, lowest velocities are measured at the end of the dry season (September) and rise rapidly following an increase in simulated pore-water pressure associated with the onset of the wet season (we generally observed a time lag of $\sim 20$ days). The landslide also exhibited a multitude of short-lived accelerations episodes, many following rainier periods during the wet seasons. Interestingly, the landslide displayed periods of acceleration after major rainfall events and maintained increased seasonal velocities for one to two months after the end of the wet season (Figs. 5e, 6a). Large acceleration phases (surges) are superimposed on these seasonal kinematic changes (Figs. 5de, 6b). Two occurred during the study period, each at a different point within the seasonal cycle, and both directly associated with landslide head retrogression episodes. Surge 1 took place in November/December 2015 during a particularly rapid phase of increasing pore-water pressure within the slope (the first portion of this wet season was wetter than usual). Surge 2 occurred just after the peak in pore-water pressure at the end of the wet season (April 2018). This pore-water pressure peak was the largest over the period 2015-2019, but other, even larger, seasonal pore-water pressure changes occurred in 2011, 2012 and 2013 without such consequences (Fig. 7; Dille et al., 2019). Lastly, we did not observe any direct influence of the nearby earthquakes on the landslide kinematics - even of the November and December 2017 Walungu earthquakes (see Fig. 2c for location) that were located only 9 and $19 \mathrm{~km}$ away.

Comparison of time series inversions performed using individual images (Supplementary Fig. 2) instead of median values from closely ( $<$ 15 days) succeeding SAR-amplitude images (Fig. 5) shows good agreement, with a slightly increased signal-to-noise ratio for the inversion with the median amplitude image. Using the median amplitude images greatly reduced the computation time by lowering the number of pairs to be computed (from 1740 to 300 , Fig. 2), but slightly decreased the temporal resolution of our time series (Fig. 2b). We recommend this
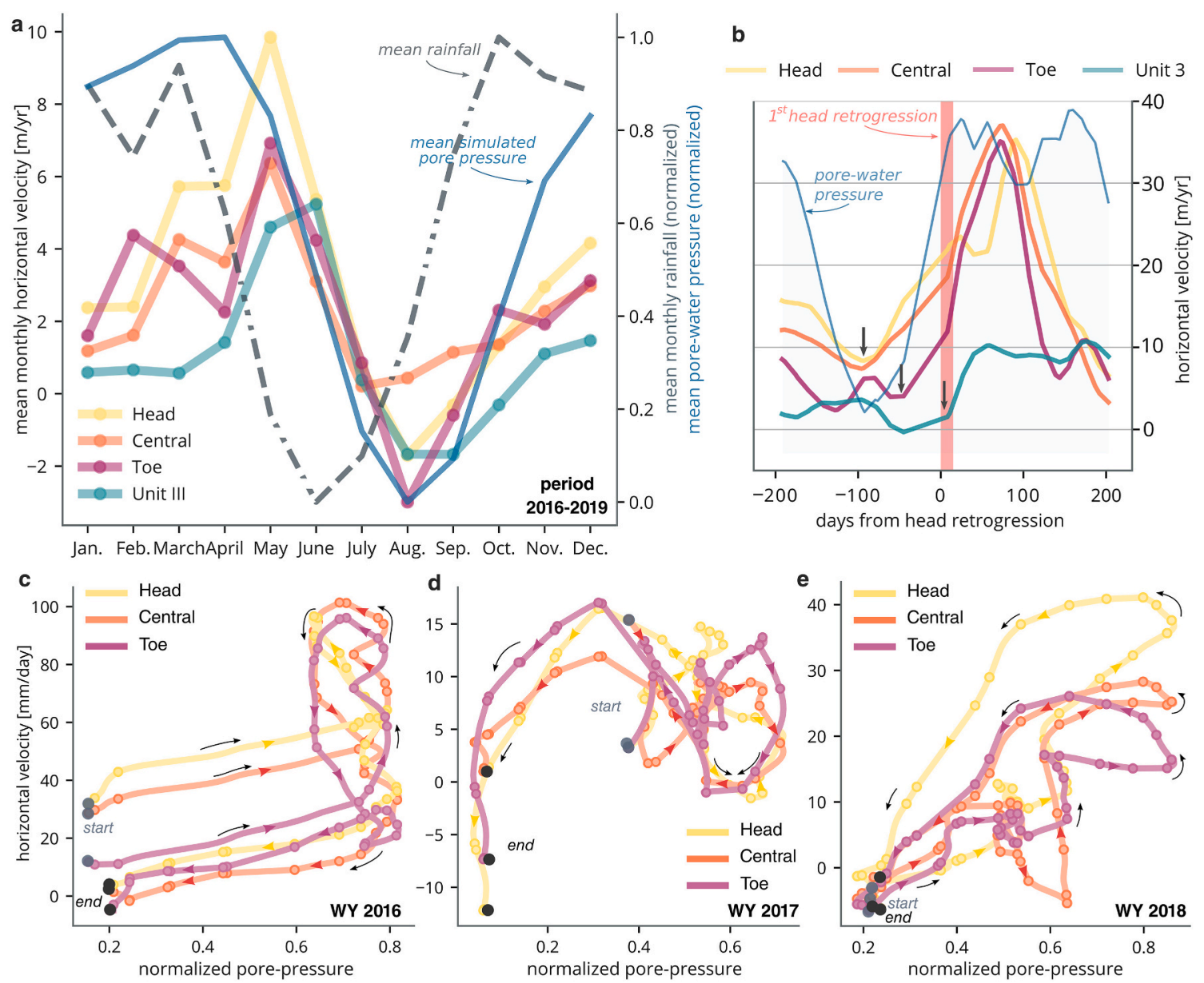

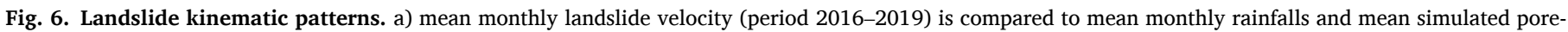

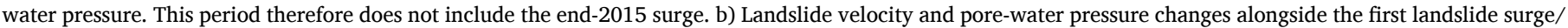

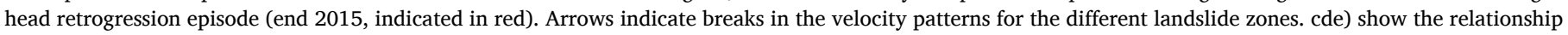

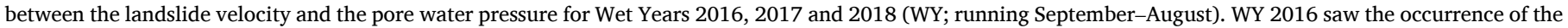
first surge and WY 2018 of the second. The scale used for plotting the landslide velocity is different for each subplot. 

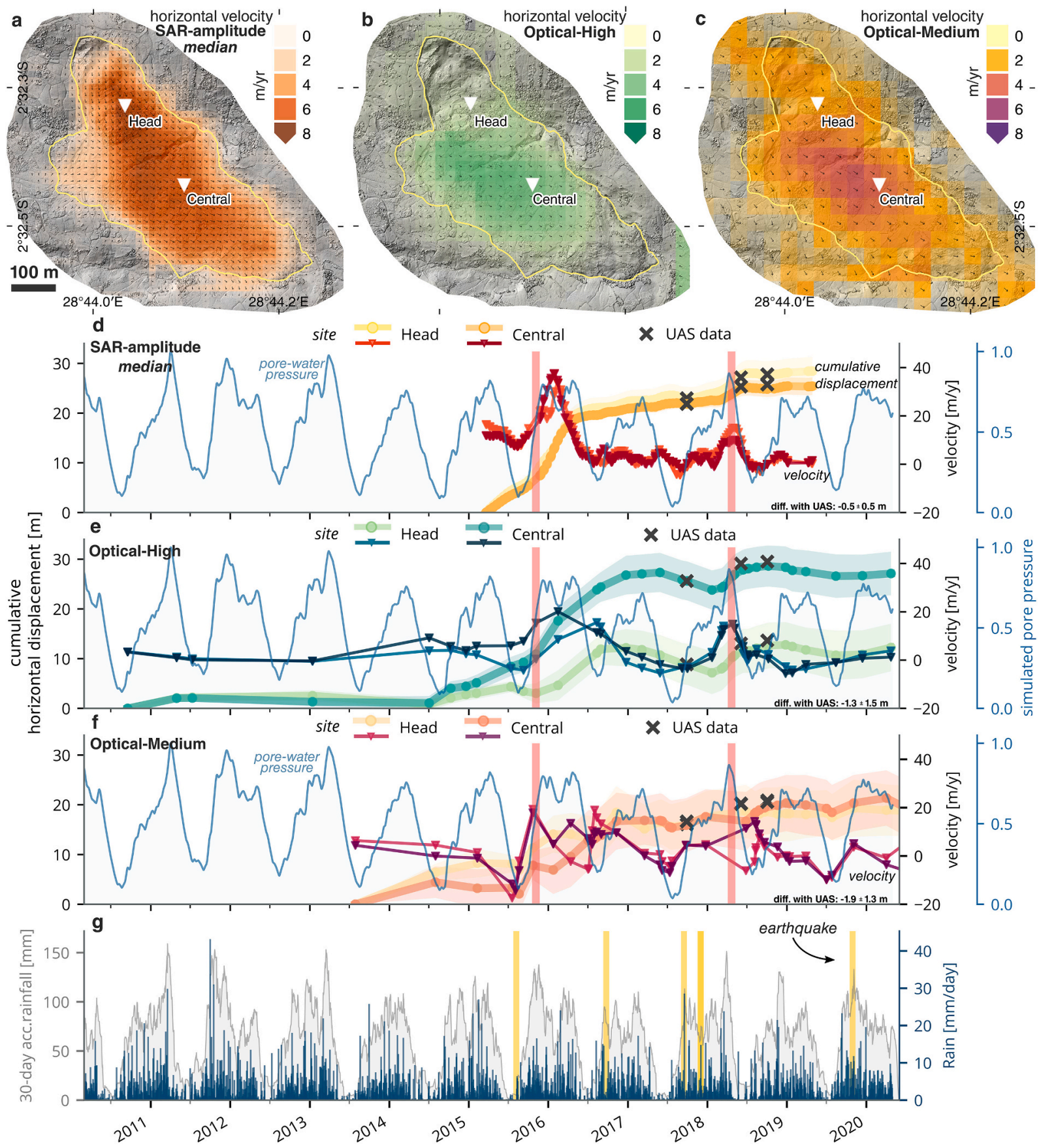

Fig. 7. Comparison between radar- and optical-based measurement of landslide motion (2010-2020). Horizontal average velocities for (a) SAR dataset (median geocoded CSK), (b) the Optical-High dataset (PlanetScope, RapidEye and Pléiades) and c the Optical-Medium dataset (Sentinel-2 and Landsat 8). def) Cumulative horizontal displacement and average horizontal velocity for the three same datasets and extracted for two individual sites within the landslide (location is shown by the triangles in abc). The blue line corresponds to the rainfall-induced changes in pore-water pressure simulated through a simple, homogenous 1D diffusion model. The black cross represents the displacement measured by UAS for the same locations (the position of the first cross has been arbitrarily set at the position of the radar cumulative displacement for easing comparison). Red bars illustrate the timing of landslide surges. Uncertainties are estimated for each site from the standard deviation of the displacement measured over the four neighbouring pixels. g) Earthquake ( $\mathrm{Mw} \geq 4.8$; distance $<50 \mathrm{~km})$ and rainfall time series for Ikoma. Rainfall data are satellite rainfall estimates from IMERG-GPM. 30-day accumulation (grey shades) and daily rain amounts (blue bars) are represented.

approach for future studies that are limited by noisy datasets. We also compared time series obtained with correlation applied on geocoded amplitude images and amplitude images in radar geometry (Supplementary Fig. 1). While no information is gathered on the vertical component of displacement with geocoded images, it provided a better spatial delineation of the velocity fields. With images in radar geometry, we observed an underestimation of the landslide motion in zones with the steepest slopes (Head and Unit III). We hypothesised that it may translate an effect of layover/foreshortening during the image correlation process. For the Central unit, the pattern and magnitude of displacements seem in accordance with the geocoded datasets.

Fig. 6 illustrates strong relationship between landslide velocity and rainfall-induced pore-water pressure changes, with periods of increased velocity generally corresponding to periods of high pore-water pressures. We sometimes observed different kinematic behaviours for the individual landslide units, both in terms of magnitude and timing of the 
kinematic changes. This is particularly true following the head unit retrogression episodes. Fig. 6b highlights the propagation of an acceleration wave through the landslide around the first surge, starting with the landslide Head and the Central unit and then spreading downslope to the landslide toe and Unit III. We also observe breaks in the velocity pattern at the time of the head retrogression. These downslope kinematic waves do not appear to occur in the absence these episodic headscarp collapses. Analysis of the relationship between landslide changes in velocity and simulated pore-water pressure shows complex, non-linear patterns that are not consistent over time (Fig. 6 cde). Rising pore-water pressure was associated with higher movement rates than falling pore-water pressure for Wet Year (WY) 2016 and 2018, which both experienced head retrogression episodes. We observed a strong velocity decrease while pore-water pressure was at very high levels for WY 2016 (Fig. 6c), but a more constant velocity while pore-water pressures were declining for WY 2018 (Fig. 6e). Patterns are less clear for WY 2017 where velocities are generally lower, but we found a reverse relationship where velocities were generally decreasing with increase in pore-water pressure and the landslide accelerated even as pore-water pressure started to fall (Fig. 6d).

Fig. 7 shows a comparison of surface velocity fields and time series of deformation for SAR and optical satellite datasets. Over the period 2015-2020, the high-resolution optical datasets (RapidEye, PlanetScope and Pléiades) showed average and maximal horizontal velocities of 1.7 and $4.4 \mathrm{~m} \mathrm{yr}^{-1}$ over the entire landslide Head unit, 2.6 and $4.8 \mathrm{~m} \mathrm{yr}^{-1}$ over the Central unit and 2.5 and $4.8 \mathrm{~m} \mathrm{yr}^{-1}$ over the Unit III. Velocities measured from the medium resolution optical dataset (Sentinel-2 and Landsat 8) were very similar, with 2.4 and $3.8 \mathrm{~m} \mathrm{yr}^{-1}$ average and maximal horizontal velocities over the landslide head, 2.8 and $4.6 \mathrm{~m}$ $\mathrm{yr}^{-1}$ over the central unit and 2.4 and $3.3 \mathrm{~m} \mathrm{yr}^{-1}$ over the third unit. Time series obtained from both optical datasets have a much lower temporal density of measurements than the one obtained with SAR data (97 and 175 offsets maps for high- and medium-resolution optics datasets, Fig. 2b), and a lower signal-to-noise ratio compared to SAR time series - which manifest as larger standard deviations in velocities for surrounding pixels, rugged patterns of displacement and velocity time series, and erroneous negative velocities (Fig. 7 ef). The average displacement difference with UAS for the four sites is $-1.3 \pm 1.5 \mathrm{~m}$ and $-1.9 \pm 1.3 \mathrm{~m}$ for Optical-High and Optical-Medium sets, respectively. Despite the lower temporal resolution and data quality, the optical datasets allowed us to examine the landslide kinematic before 2015. We found that the landslide was stable between 2010 and mid-2013. Surge 1 and related acceleration is clearly observed by both optical datasets, but the timing of Surge 2 was missed because of an absence of cloud-free images at that time. While an underestimation of the surface displacement over the head unit is observed for both optical datasets, the overall pattern of motion is otherwise captured.

\section{Discussion}

\subsection{Controls on the landslide kinematics}

Slow-moving landslides generally exhibit highly variable velocities in space and time (Massey et al., 2013; Lacroix et al., 2020), and Ikoma is no exception. Sub-pixel image correlation applied to SAR-amplitude images confidently resolved landslide surface velocities, offering spatially and temporally dense kinematic data making possible the identification of mechanisms and controls on the landslide kinematics over a large range of timescales. We observed velocity changes that included seasonal variations, transient acceleration episodes, episodic failure events and multi-year trends (Figs. 5-7). Similar to many other landslides (e.g., Handwerger et al., 2013; Carey et al., 2019), these kinematic changes are closely tied to variations in pore-water pressure within the landslide. The landslide response to rainfall-induced porewater pressure changes is non-linear, and we generally observed a time lag of $\sim 20$ days between onset of rainfall and landslide acceleration that we infer is related to the time it takes for an increase in pore-water pressure to propagate to the basal sliding surface (e.g., Hilley et al., 2004; Figs. 5e, 6a). This time lag is short compared to most deep-seated landslides, for which prolonged periods often exceeding a month of increased rainfall are usually necessary to trigger acceleration (Iverson and Major, 1987; Malet et al., 2002; Hilley et al., 2004; Handwerger et al., 2013; Massey et al., 2013). We also found that the influence of rainfall on the landslide velocity is long-lasting, with the peak motion occurring, on average, during the end of the wet season when rainfall amounts are already in the decrease towards the dry season (Fig. 6a). It is at that moment of the year that most landslides are reported in the region (Monsieurs et al., 2018). Such a faster landslide response to a rise in pore-water pressure than to a fall in pore-water pressure translates hysteresis pattern over seasonal timescales (Carey et al., 2019). Such behaviours are however not unique (e.g., Malet et al., 2002; Corominas et al., 2005), and our very-dense time series may capture a response that is usually missed with the lower sampling frequency of conventional InSAR or satellite optical measurements.

Interestingly, we found that rapid acceleration of the landslide occurs both at the onset of the wet season (when groundwater table is expected to be at its lowest) and during periods of intense rainfall during the wet season (when groundwater table level is expected to be high). These changes in landslide kinematics suggest that minor changes in effective stress control changes in velocity (Schulz et al., 2009b), with the landslide remaining close to an acceleration threshold all year long (Iverson and Major, 1987; Hilley et al., 2004). This observation is consistent with the landslide "bathtub hypothesis", whereby landslides remain wet year-round because low-permeability shear zones that prevent groundwater drainage and hydrologically isolate landslides from their surroundings (Baum and Reid, 2000; Nereson et al., 2018). Evidence of the "bathtub" is provided by Dille et al. (2019), who observed slickensided clay-gauges at the contact between basaltic layers. Furthermore, these low permeability layers are believed to have played a role in the early destabilisation of the slope (Dille et al., 2019).

We did not observe any direct landslide accelerations following nearby large earthquakes. However, these earthquakes occurred at the end of the dry season or early into the wet seasons when pore-water pressures were relatively low. Several months after the largest earthquakes occurred the two surges/head retrogressions. While our data showed that the earthquakes did not directly trigger accelerations, they may have caused weakening of the landslide material that promoted further destabilisation during the following (particularly) wet seasons. More work is needed to better understand the combined role of earthquakes and precipitation, which have been shown to work together to promote instability of slow-moving landslides (e.g., Bontemps et al., 2020).

While the entire landslide seems sensitive to both short and prolonged (seasonal) water inputs, velocity changes do not appear synchronously along the landslide body. It is well illustrated by the propagation of an acceleration wave alongside head retrogression episodes (Head $>$ Central $>$ Toe $>$ Unit III; Fig. 6b). The order of the acceleration sequence suggests a stress propagation mechanisms similar as the one proposed for the initial landslide failure (Dille et al., 2019): i.e., undrained loading from material accumulation at the foot of the Head unit increased the shear stress and triggered the movement of Central unit that propagated to the landslide toe, and finally removed support and triggered acceleration of Unit III. We observed delayed accelerations up to $\sim 100$ days between units when movement is driven by undrained loading. We also found that units with the smallest inferred depth (Fig. 4i) reacted last to changing precipitations, which suggests that internal mass redistribution and stress transfer are here more important than the (a priori) spatially uniform stress perturbation induced by rainfalls. This sequence emphasizes the importance of changing stability of the landslide head - that affects kinematics therein and downslope, but also of considering internal landslide dynamics alongside the effect of external forcings (e.g., Schulz et al., 2017). 
The analysis of the complex relationship between pore-water and velocity changes also highlights the importance of local conditions associated with landslide geometry, material properties or stress transfer between units. For WY2016, we observed that both periods of landslide acceleration and deceleration occurred during the peak in pore-water pressure (Fig. 6c). This (rapid) velocity decrease under high and increasing pore-water pressure (i.e., important stress forcing) suggests that the landslide is controlled by strain-hardening or velocitystrengthening friction which acts to prevent runaway acceleration (van Asch et al., 2007; Petley et al., 2017; Booth et al., 2018; Handwerger et al., 2019a). Interestingly, the opposite behaviour is observed for WY2017 and WY2018 (Fig. 6 de), with velocities that are comparatively low as pore-water pressure increases (and peaks) and high as it decreases, suggesting that frictional resistance decreases with displacement (strain weakening behaviour; Petley et al., 2017). This change in frictional behaviour for the different WY implies that large strains can change the landslide material response (van Asch et al., 2007; Handwerger et al., 2016; Petley et al., 2017), and show that the landslide kinematics are influenced by local conditions and internal dynamics associated with movement and stress transfer between units (Petley et al., 2017). These diverse behaviours highlight the complex kinematics exhibited by slow-moving landslides and the challenges entailed in predicting the velocity of landslides (Booth et al., 2020).

The complex spatiotemporal velocity pattern is well illustrated in Fig. 8, which shows radar-based estimates of the quarterly horizontal landslide velocity. These maps illustrate well the succession of periods of

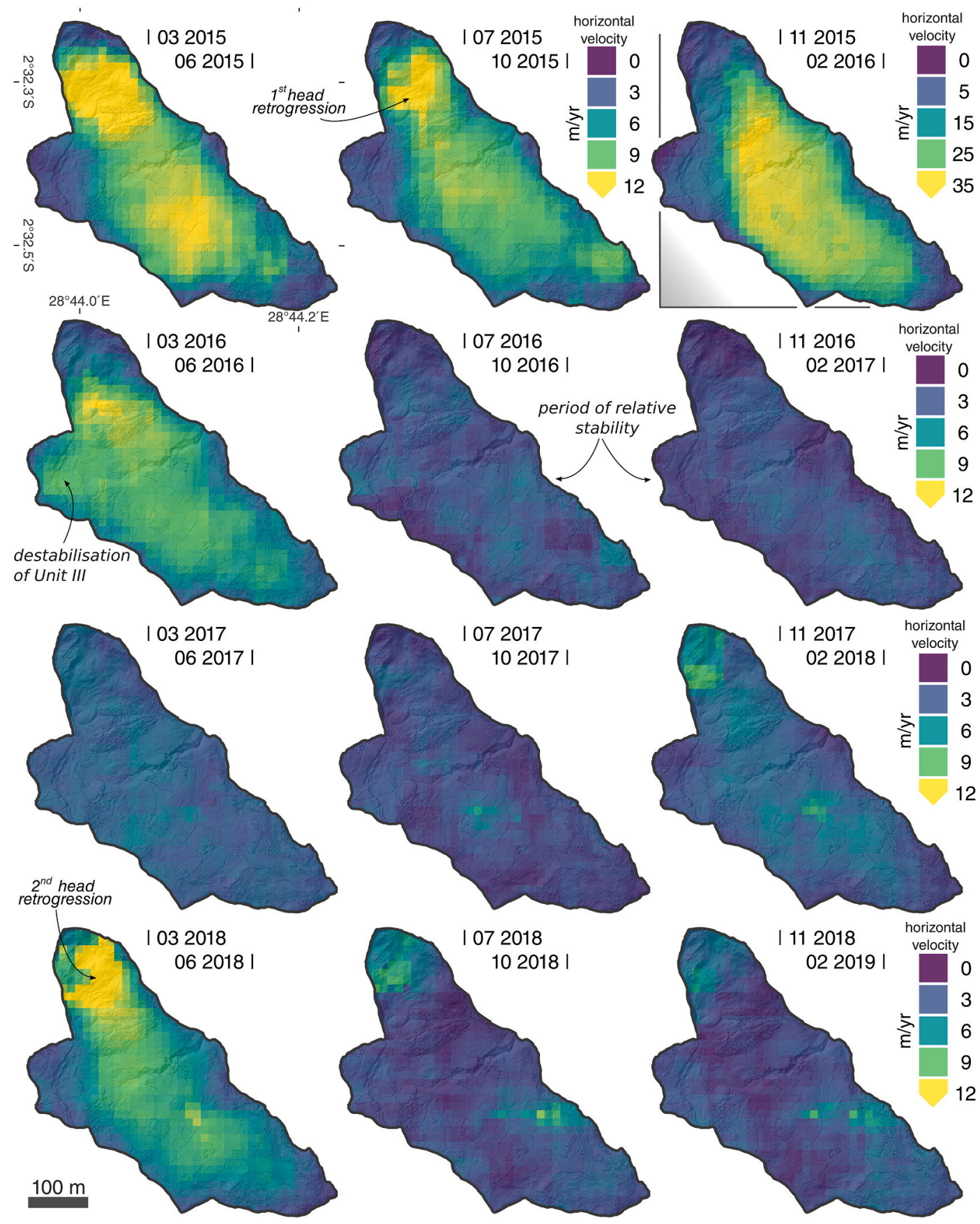

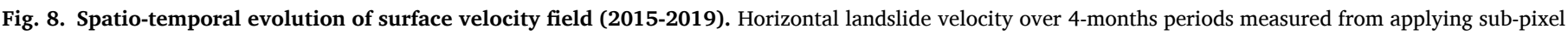

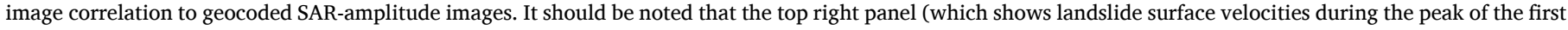
surge) has a distinct legend scale. 
relative quiescence and episodic instabilities, emphasizing that the entire landslide is not active at all time and highlighting the important intra-unit velocity variations over time.

While the Ikoma landslide's kinematic is today primarily controlled by rainfall-induced pore-water pressure changes in the slope, phases of instability that shaped the landslide are thought to be intrinsically related to process of hillslope evolution rather than a defined trigger event (Dille et al., 2019). Local conditions (e.g., tropical climate and lithology favouring deep weathering and low shear strength) have reinforced the role of the so-called underlying causes to landsliding, that seemed ultimately the primary cause of previous failures (Dille et al., 2019). This is, however, not necessarily conflicting with today's behaviour considering how the failures have completely transformed hillslope stress conditions. An example is provided by the landslide sensibility to peaks in pore-water pressure: peaks $10-15 \%$ larger than the one that triggered Surge 2 occurred in 2011, 2012 and 2013 without such consequences (Fig. 7; Dille et al., 2019). Modifications to the slope geometry/stress field caused by Surge 1 are likely responsible to this change in behaviour of the landslide. Hence, emphasising the particular importance of underlying landslide causes in contexts favouring rapid weakening of the slope mechanical properties do not discount the importance of external forcing to explain the complete evolution of the hillslope, but stresses the relevance of considering multiple dynamic Earth processes and their interactions at different time scales to unravel hillslope development processes.

\subsection{Image correlation for measuring landslide motion}

We created a dense set of kinematic data for Ikoma landslide from a combination of sub-pixel image correlation and time series inversion of UAS, SAR-amplitude and optical satellite data. All provided satisfactory records of the multi-year landslide motion (Figs. 4-8). Yet, all datasets are not equivalent to improving our understanding of the processes controlling landslide motion. While UAS data provides topographic and deformation products with unmatched spatial resolution and accuracy -prime tools for picturing the landslide mechanisms (Booth et al., 2018; Dille et al., 2019), multi-temporal data collection is time consuming, limiting the prospects to characterise kinematics from UAS data (Eltner et al., 2016). The use of optical satellite images provides an already much better temporal resolution that can capture the main kinematic behaviours. Yet, noise in the time series due to coregistration and orthorectification errors, surface changes, intrinsic limits of correlation, etc., and a comparatively low temporal sampling prevented clear identification of timing of key phases of landslide motion when compared to the SAR data. Therefore, we find that SAR-amplitude images offer the best balance between high-temporal and high-spatial resolution deformation measurements and encourage the use of sub-pixel image correlation to monitor landslides for future studies. Internal dynamics and interactions between landslide units are captured and the all-weather/ day-night capabilities of active sensor provide time series with very few temporal gaps. Overall, we showed this last method to be particularly adapted for the analysis of highly variable process in space and time such as landslides.

Because dense time series are key to the identification of transient surface processes, it is necessary to utilize data with a high temporal sampling. By integrating offset maps measured over different time spans - as it is usually done in a standard InSAR workflow - we were able to exploit the redundancy of displacement fields and derive robust and dense displacement time series from both SAR-amplitude and optical images. We could further improve temporal sampling (and data redundancy) by integrating together offset maps of optical sensors with roughly the same resolution (respectively into Optical-High and OpticalMedium sets), and offset maps obtained from the correlations of ascending and descending radar sets (Fig. 2b, 3; Supplementary Figs. 4, $5,6)$. Alongside an increased temporal sampling, the integration and reconstruction of time series of ground deformation from velocities measured over different time spans averages out the effect of various sources of noise (e.g., topographic, orbital, etc.) improving the signal-tonoise ratio (Samsonov and d'Oreye, 2012). While recent sensors constellations such as PlanetScope and Sentinel-2 theoretically offer sub- to weekly temporal sampling, the number of operational scenes is inherently limited by the cloud cover - almost persistent during wet season(s) in tropical regions. Restricting our optical sets to scenes where the landslide was free of clouds, we essentially used images acquired during the dry season, restricting the identification of temporally variable dynamic controls. Also, as sufficient displacement (that varies in function of the pixel size of the image used) is required for accurate measurements, slow landslides may require long time span of offset maps before being able to measure any motion, which can further greatly reduce the temporal sampling with medium resolution images. The overall quality of the optical datasets was also limited by our relatively simple workflow, where pre-orthorectified images with (unconstrained) topographic bias are used. A stricter data preparation (i.e., using the same highresolution DSM for in-house orthorectification and co-registration, correction of co-registration artefacts, outlier removal by applying filters, etc.; e.g., Stumpf et al., 2017, 2018; Bontemps et al., 2018; Altena et al., 2019) should improve individual offset maps and the overall accuracies. Generally, the slower the displacement to measure the more crucial is a stricter procedure. Using more images from very-highresolution and quality sensors such as Pléiades would certainly have provided higher quality optical outputs (e.g., Stumpf et al., 2014, 2017) but they are costly and especially difficult to obtain at regular intervals in tropical regions (Dewitte et al., 2021).

Our work demonstrates the interest of applying a combination of sub-pixel image correlation and time series inversions on long series of SAR-amplitude images to obtain detailed measurements of landslide motion. While we had to rely on satellite remote sensing for studying the dynamics of Ikoma landslide, neither traditional methods such as image correlation applied on optical satellite (impeded by the frequent cloud cover) nor SAR interferometry (made impracticable by the meter per month velocities and the rapidly changing vegetation cover) were able to provide such dense time series of landslide motion. The characteristics of the SAR-amplitude data (low dependence to weather conditions, repetitiveness, spatial resolution, etc.) make them particularly wellsuited to study surface processes in zones affected by persistent cloud cover. But the characteristics of the kinematic datasets collected (e.g., high-spatial and sub-weekly temporal resolution, ability to measure meter per month velocity surges, good signal-to-noise ratio, etc.) stress that time series of SAR-amplitude images should also be considered as performing alternative for landslide studies elsewhere on the globe. The simple workflow proposed here builds only on existing tools and can easily be applied on other targets. Even where high-resolution SAR images are not available, we believe that offsets obtained from Sentinel1 images can provide insights for many large landslides. Focusing on Sentinel-1 range offsets only ( $2.7 \mathrm{~m}$ resolution) will in addition already provide deformation maps with a fairly high spatial (and temporal) resolution (e.g., Sánchez-gámez and Navarro, 2017).

While offering much lower temporal sampling, optical satellite data has here been able to highlight the landslide acceleration associated with the main instability phases. The availability of historical (very-) high-resolution satellite and airborne optical images around most places of the globe moreover offers invaluable insights to understand the history of hillslope failures (e.g., Bennett et al., 2016; Dille et al., 2019). While research usually focuses on the use of either optical or radar wavelengths, detailed kinematic measurements will always benefit from taking advantage of synergies between both imaging techniques, that complement each other drawbacks and increase the frequency of measurements (Lacroix et al., 2020). This will ensure a better exploitation of the large and growing archive of repeat satellite imagery, as well as better meet the increasing needs to quantify and monitor landslides around the globe. 


\section{Conclusion}

We used UAS, SAR-amplitude and optical satellite data to unravel the complex dynamics of a landslide located in the tropical Kivu Rift. We applied a combination of sub-pixel image correlation and time series inversion to measure landslide ground surface deformation and examined important landslide forcings such as rainfall, simulated pore-water pressure, undrained loading, and nearby earthquakes. Our kinematic dataset showed that rainfall-induced pore-water pressure exerts the main control on the landslide motion. Yet, we also found that external forcings alone cannot explain all of the observed kinematic variability, emphasizing that internal landslide dynamics (extension, compression, material redistribution, etc.) and interactions between kinematic units exert strong control on the landslide motion. These complex behaviours highlight the challenge in predicting the velocity of landslides. We would not have been able to identify and monitor the landslide kinematics with the same level of characterisation using SAR interferometry or optical satellite images alone due to constraints brought by the landslide velocity, rapidly changing surface and the persistence of a dense cloud cover during the long wet season. The combination of subpixel offset tracking and time-series inversion on SAR-amplitude images thus represents a performing alternative for the characterisation of landslide motion - and not only for landslides in tropical regions.

Long-term, detailed characterisation of landslide kinematics remains rare and generally concerns a few case studies in high-income countries (Schulz et al., 2009b; Lacroix et al., 2020) that are not representative for the diversity of environmental conditions (climate, tectonic, lithology, weathering, etc.) and external forcings (rainfalls, earthquakes, human influence, etc.) that impact landslide activity. While local knowledge and field characterisation will always remain crucial, available tools and the large and growing archive of repeat satellite imagery offer opportunities to meet the needs to quantify and monitor landslides all around the globe. Quantifying the controls on landslide motion is essential for characterising how surface processes influence paces of landscape evolution and the accurate evaluation of the landslide hazard. While mountain regions of the tropics tend to be disproportionately impacted by landslides (Froude and Petley, 2018; Emberson et al., 2020; Lacroix et al., 2020), we believe the information gathered in this study will help the understanding of these processes not only in the particularly datascarce Kivu Rift region but also across regions where similar environmental conditions are met.

\section{Author contribution}

A.D. conceived the study with inputs from O.D., F.K. and M.K.; A.D. processed and analysed the data and created the figs. A.D. wrote the manuscript, with main inputs from O.D. and key contributions from M. K. and A.H.; A.D., O.D., F.K. and T.M.B. participated in the field data acquisition and interpretation. N.dO., D.D. and S.S. assisted the processing of SAR data. A.H. and JP.M. assisted in the interpretation of the results. A.H. assisted the processing of slope pore-water simulations and landslide depth estimations. All the authors contributed to the final version of the paper. O.D. and F.K. coordinated and designed this collaborative study in the frame of the RESIST and MODUS projects.

\section{Declaration of Competing Interest}

None.

\section{Acknowledgements}

This article is a contribution in the framework of the project RESIST funded by the Belgian Science Policy (BELSPO), Belgium (SR/00/305) and the Fonds National de la Recherche, Luxembourg (INTER/STEREOIII/13/05/RESIST/d'Oreye); MODUS (SR/00/358), AfReSlide (BR/ 121/A2/AfReSlide) and PAStECA (BR/165/A3/PASTECA) research projects funded by BELSPO and RA_S1_RGL_GEORISK and HARISSA funded by the Development Cooperation program of the Royal Museum for Central Africa (Belgium) with support of the Directorate-general Development Cooperation and Humanitarian Aid of Belgium (Belgium). COSMO-SkyMed images were acquired through RESIST and MODUS projects as well as the CEOS Landslide Pilot. The images are under an Italian Space Agency (ASI) licence. Special thanks go to the Université Officielle de Bukavu, and particularly to the members of the Department of Geology. Together with the support of the Civil Protection of South Kivu, they made possible to execute fieldwork in the study area and were part of many discussions on landslide processes in the area. Part of this research was performed at the Jet Propulsion Laboratory, California Institute of Technology under contract with NASA. We thank Damien Delvaux for sharing field pictures and discussions on the tectonic and geology of the area. We further wish to thank Georgina Bennett, Pablo Gonzalez and Martin Rutzinger for their insightful discussions and recommendations regarding this research.

\section{Appendix A. Supplementary data}

Supplementary data to this article can be found online at https://doi. org/10.1016/j.rse.2021.112402.

\section{References}

Agisoft, 2020. Agisoft Metashape Pro.

Alberti, S., Senogles, A., Kingen, K., Booth, A., Castro, P., DeKoekkoek, J., GloverCutter, K., Mohney, C., Olsen, M., Leshchinsky, B., 2020. The Hooskanaden landslide: historic and recent surge behavior of an active earthflow on the Oregon coast. Landslides. https://doi.org/10.1007/s10346-020-01466-8.

Albino, F., Smets, B., D’Oreye, N., Kervyn, F., 2015. High-resolution TanDEM-X DEM: An accuratemethod to estimate lava flowvolumes at Nyamulagira Volcano (D. R. Congo). J. Geol. Res. Solid Earth 120. https://doi.org/10.1002/2015JB011988.

Altena, B., Scambos, T., Fahnestock, M., Kääb, A., 2019. Extracting recent short-term glacier velocity evolution over southern Alaska and the Yukon from a large collection of Landsat data. Cryosphere 13, 795-814. https://doi.org/10.5194/tc-13795-2019.

Amitrano, D., Guida, R., Dell'Aglio, D., Di Martino, G., Di Martire, D., Iodice, A., Costantini, M., Malvarosa, F., Minati, F., 2019. Long-term satellite monitoring of the Slumgullion landslide using space-borne synthetic aperture radar sub-pixel offset tracking. Remote Sens. 11, 369. https://doi.org/10.3390/rs11030369.

van Asch, T.W.J., Van Beek, L.P.H., Bogaard, T.A., 2007. Problems in predicting the mobility of slow-moving landslides. Eng. Geol. 91, 46-55. https://doi.org/10.1016/ j.enggeo.2006.12.012.

Avouac, J.P., Leprince, S., 2015. Geodetic Imaging Using Optical Systems, Treatise on Geophysics, Second edition. Elsevier B.V. https://doi.org/10.1016/B978-0-44453802-4.00067-1.

Baum, R.L., Reid, M.E., 2000. Ground water isolation by low-permeability clays in landslide shear zones. Landslides Res. Theory Pract. 1, 139-144.

Baum, R.L., Messerich, J., Fleming, R.W., 1998. Surface deformation as a guide to kinematics and three-dimensional shape of slow-moving, clay-rich landslides, Honolulu. Hawaii. Environ. Eng. Geosci. 4, 283-306.

Bennett, G.L., Roering, J.J., Mackey, B.H., Handwerger, A.L., Schmidt, D.A., Guillod, B. P., 2016. Historic drought puts the brakes on earthflows in northern California. Geophys. Res. Lett. 43, 5725-5731. https://doi.org/10.1002/2016GL068378.

Berardino, P., Fornaro, G., Lanari, R., Sansosti, E., 2002. A new algorithm for surface deformation monitoring based on small baseline differential SAR interferograms. IEEE Trans. Geosci. Remote Sens. 40, 2375-2383. https://doi.org/10.1109/ TGRS.2002.803792.

Bontemps, N., Lacroix, P., Doin, M.P., 2018. Inversion of deformation fields time-series from optical images, and application to the long term kinematics of slow-moving landslides in Peru. Remote Sens. Environ. 210, 144-158. https://doi.org/10.1016/j. rse.2018.02.023.

Bontemps, N., Lacroix, P., Larose, E., Jara, J., Taipe, E., 2020. Rain and small earthquakes maintain a slow-moving landslide in a persistent critical state. Nat. Commun. 11, 780. https://doi.org/10.1038/s41467-020-14445-3.

Booth, A.M., Lamb, M.P., Avouac, J.P., Delacourt, C., 2013. Landslide velocity, thickness, and rheology from remote sensing: La Clapiere landslide. France. Geophys. Res. Lett. 40, 4299-4304. https://doi.org/10.1002/grl.50828.

Booth, A.M., McCarley, J., Hinkle, J., Shaw, S., Ampuero, J.-P., Lamb, M.P., 2018. Transient reactivation of a deep-seated landslide by Undrained loading captured with repeat airborne and terrestrial Lidar. Geophys. Res. Lett. 45, 4841-4850. https://doi.org/10.1029/2018GL077812.

Booth, A.M., McCarley, J.C., Nelson, J., 2020. Multi-year, three-dimensional landslide surface deformation from repeat lidar and response to precipitation: Mill Gulch earthflow, California. Landslides 17, 1283-1296. https://doi.org/10.1007/s10346020-01364-z. 
Carey, J.M., Massey, C.I., Lyndsell, B., Petley, D.N., 2019. Displacement mechanisms of slow-moving landslides in response to changes in porewater pressure and dynamic stress. Earth Surf. Dyn. 7, 707-722. https://doi.org/10.5194/esurf-7-707-2019.

Clapuyt, F., Vanacker, V., Schlunegger, F., Van Oost, K., 2017. Unravelling earth flow dynamics with 3-D time series derived from UAV-SfM models. Earth Surf. Dyn. 5, 791-806. https://doi.org/10.5194/esurf-5-791-2017.

Cohen-Waeber, J., Bürgmann, R., Chaussard, E., Giannico, C., Ferretti, A., 2018. Spatiotemporal patterns of precipitation-modulated landslide deformation from independent component analysis of InSAR time series. Geophys. Res. Lett. 45, 1878-1887. https://doi.org/10.1002/2017GL075950.

Cook, K.L., Dietze, M., 2019. Short communication: a simple workflow for robust lowcost UAV-derived change detection without ground control points. Earth Surf. Dyn. 7, 1009-1017. https://doi.org/10.5194/esurf-7-1009-2019.

Corominas, J., Moya, J., Ledesma, A., Lloret, A., Gili, J.A., 2005. Prediction of ground displacements and velocities from groundwater level changes at the Vallcebre landslide (Eastern Pyrenees, Spain). Landslides 2, 83-96. https://doi.org/10.1007/ s10346-005-0049-1.

De Michele, M., Raucoules, D., De Sigoyer, J., Pubellier, M., Chamot-Rooke, N., 2010. Three-dimensional surface displacement of the 2008 May 12 Sichuan earthquake (China) derived from Synthetic Aperture Radar: evidence for rupture on a blind thrust. Geophys. J. Int. 183, 1097-1103. https://doi.org/10.1111/j.1365246X.2010.04807.x.

Debella-Gilo, M., Kääb, A., 2011. Sub-pixel precision image matching for measuring surface displacements on mass movements using normalized cross-correlation. Remote Sens. Environ. 115, 130-142. https://doi.org/10.1016/j.rse.2010.08.012.

Delacourt, C., Allemand, P., Casson, B., Vadon, H., 2004. Velocity field of the "La Clapière" landslide measured by the correlation of aerial and QuickBird satellite images. Geophys. Res. Lett. 31, 1-5. https://doi.org/10.1029/2004GL020193.

Delacourt, C., Allemand, P., Berthier, E., Raucoules, D., Casson, B., Grandjean, P. Pambrun, C., Varel, E., 2007. Remote-sensing techniques for analysing landslide kinematics: a review. Bull. Soc. Geol. Fr. 178, 89-100. https://doi.org/10.2113/ gssgfbull.178.2.89.

Delbridge, B.G., Bürgmann, R., Fielding, E., Hensley, S., Schulz, W.H., 2016. Threedimensional surface deformation derived from airborne interferometric UAVSAR: application to the Slumgullion landslide. J. Geophys. Res. Solid Earth 121, 3951-3977. https://doi.org/10.1002/2015JB012559.

Delvaux, D., Mulumba, J.-L.L., Sebagenzi, M.N.S., Bondo, S.F., Kervyn, F., Havenith, H.B.B., 2017. Seismic hazard assessment of the Kivu rift segment based on a new seismotectonic zonation model (western branch, East African Rift system). J. Afr. Earth Sci. 134, 831-855. https://doi.org/10.1016/j.jafrearsci.2016.10.004.

Depicker, A., Jacobs, L., Delvaux, D., Havenith, H.-B., Maki Mateso, J.-C., Govers, G., Dewitte, O., 2020. The added value of a regional landslide susceptibility assessment: the western branch of the East African Rift. Geomorph. 353, 17. https://doi.org/ 10.1016/j.geomorph.2019.106886.

Derauw, D., Nicolas, D., Jaspard, M., Caselli, A., Samsonov, S., 2020. Ongoing automated ground deformation monitoring of Domuyo - Laguna del Maule area (Argentina) using Sentinel-1 MSBAS time series: methodology description and first observations for the period 2015-2020. J. S. Am. Earth Sci. 104, 102850. https://doi.org/ 10.1016/j.jsames.2020.102850.

Dewitte, O., Dille, A., Depicker, A., Kubwimana, D., Maki Mateso, J.-C., Mugaruka Bibentyo, T., Uwihirwe, J., Monsieurs, E., 2021. Constraining landslide timing in a data-scarce context: from recent to very old processes in the tropical environment of the North Tanganyika-Kivu Rift region. Landslides 18, 161-177. https://doi.org/ 10.1007/s10346-020-01452-0.

Dewitte, O., Jasselette, J.C., Cornet, Y., Van Den Eeckhaut, M., Collignon, A., Poesen, J., Demoulin, A., 2008. Tracking landslide displacements by multi-temporal DTMs: a combined aerial stereophotogrammetric and LIDAR approach in western Belgium. Eng. Geol. 99, 11-22. https://doi.org/10.1016/j.enggeo.2008.02.006.

Dille, A., Kervyn, F., Mugaruka Bibentyo, T., Delvaux, D., Ganza, G.B., Ilombe Mawe, G., Kalikone Buzera, C., Safari Nakito, E., Moeyersons, J., Monsieurs, E., Nzolang, C., Smets, B., Kervyn, M., Dewitte, O., 2019. Causes and triggers of deep-seated hillslope instability in the tropics - Insights from a 60-year record of Ikoma landslide (DR Congo). Geomorph. 345, 13. https://doi.org/10.1016/j.geomorph.2019.106835.

Dzurisin, D., Lu, Z., 2006. Interferometric synthetic-aperture radar (InSAR). In: Dzurisin, D. (Ed.), Volcano Deformation: New Geodetic Monitoring Techniques. Springer Science \& Business Media.

Elliott, J.R., de Michele, M., Gupta, H.K., 2020. Earth observation for crustal tectonics and earthquake hazards. Surv. Geophys. https://doi.org/10.1007/s10712-02009608-2.

Elliott, J.R., Walters, R.J., Wright, T.J., 2016. The role of space-based observation in understanding and responding to active tectonics and earthquakes. Nat. Commun. 7 , 1-16. https://doi.org/10.1038/ncomms13844.

Eltner, A., Kaiser, A., Castillo, C., Rock, G., Neugirg, F., Abellán, A., 2016. Image-based surface reconstruction in geomorphometry-merits, limits and developments. Earth Surf. Dyn. 4, 359-389. https://doi.org/10.5194/esurf-4-359-2016.

Emberson, R., Kirschbaum, D., Stanley, T., 2020. New global characterization of landslide exposure. Nat. Hazards Earth Syst. Sci. 30, 1-21. https://doi.org/10.5194/ nhess-2019-434.

Fielding, E.J., Liu, Z., Stephenson, O.L., Zhong, M., Liang, C., Moore, A., Yun, S.H., Simons, M., 2020. Surface deformation related to the 2019 Mw7.1 and 6.4 ridgecrest earthquakes in california from GPS, SAR interferometry, and SAR pixel offsets. Seismol. Res. Lett. 91, 2035-2046. https://doi.org/10.1785/0220190302.

Froude, M.J., Petley, D.N., 2018. Global fatal landslide occurrence from 2004 to 2016. Nat. Hazards Earth Syst. Sci. 18, 2161-2181. https://doi.org/10.5194/nhess-182161-2018.
Guo, L., Li, J., Li, Zhi-wei, Wu, L., Li, X., Hu, J., Li, Hui-lin, Li, Hong-yi, Miao, Z., Li, Zhong-qin, 2020. The surge of the Hispar glacier, Central Karakoram: SAR 3-D flow velocity time series and thickness changes. J. Geophys. Res. Solid Earth 125. https://doi.org/10.1029/2019JB018945.

Handwerger, A.L., Roering, J.J., Schmidt, D.A., 2013. Controls on the seasonal deformation of slow-moving landslides. Earth Planet. Sci. Lett. 377-378, 239-247. https://doi.org/10.1016/j.epsl.2013.06.047.

Handwerger, A.L., Roering, J.J., Schmidt, D.a., Rempel, A.W., 2015. Kinematics of earthflows in the northern California coast ranges using satellite interferometry. Geomorph. 246, 321-333. https://doi.org/10.1016/j.geomorph.2015.06.003.

Handwerger, A.L., Rempel, A.W., Skarbek, R.M., Roering, J.J., Hilley, G.E., 2016. Rateweakening friction characterizes both slow sliding and catastrophic failure of landslides. Proc. Natl. Acad. Sci. 113, 10281-10286. https://doi.org/10.1073/ pnas.1607009113.

Handwerger, A.L., Fielding, E.J., Huang, M.H., Bennett, G.L., Liang, C., Schulz, W.H., 2019a. Widespread initiation, reactivation, and acceleration of landslides in the northern California coast ranges due to extreme rainfall. J. Geophys. Res. Earth Surf. 124, 1782-1797. https://doi.org/10.1029/2019JF005035.

Handwerger, A.L., Huang, M.-H.H., Fielding, E.J., Booth, A.M., Bürgmann, R., 2019b. A shift from drought to extreme rainfall drives a stable landslide to catastrophic failure. Sci. Rep. 9, 1-12. https://doi.org/10.1038/s41598-018-38300-0.

Hendrickx, H., De Sloover, L., Stal, C., Delaloye, R., Nyssen, J., Frankl, A., 2020. Talus slope geomorphology investigated at multiple time scales from high-resolution topographic surveys and historical aerial photographs (Sanetsch Pass, Switzerland). Earth Surf. Process. Landf. https://doi.org/10.1002/esp.4989.

Hilley, G., Bürgmann, R., Ferretti, A., Rocca, F., Novali, F., 2004. Dynamics of slowmoving landslides from permanent scatterer analysis. Science (80-. ) 304 1952-1955.

Hooper, A.J., 2008. A multi-temporal InSAR method incorporating both persistent scatterer and small baseline approaches. Geophys. Res. Lett. 35, 1-5. https://doi. org/10.1029/2008GL034654.

Hu, J., Li, Z.W.W., Ding, X.L.L., Zhu, J.J.J., Zhang, L., Sun, Q., 2014. Resolving threedimensional surface displacements from InSAR measurements: a review. EarthScience Rev. 133, 1-17. https://doi.org/10.1016/j.earscirev.2014.02.005.

Hu, X., Bürgmann, R., Fielding, E.J., Lee, H., 2020a. Internal kinematics of the Slumgullion landslide (USA) from high-resolution UAVSAR InSAR data. Remote Sens. Environ. 251, 112057. https://doi.org/10.1016/j.rse.2020.112057.

Hu, X., Bürgmann, R., Schulz, W.H., Fielding, E.J., 2020b. Four-dimensional surface motions of the Slumgullion landslide and quantification of hydrometeorological forcing. Nat. Commun. 11, 1-9. https://doi.org/10.1038/s41467-020-16617-7.

Huffman, G., Bolvin, D., Braithwaite, D., Hsu, K., Joyce, R., 2019. NASA global precipitation measurement - integrated multi-satellite retrievals for GPM. Algorithm Theoretical Basis Document v06.

Hungr, O., Leroueil, S., Picarelli, L., 2014. The Varnes classification of landslide types, an update. Landslides 11, 167-194. https://doi.org/10.1007/s10346-013-0436-y.

Iverson, R.M., 2000. Landslide triggering by rain infiltration. Water Resour. Res. 36, 1897-1910. https://doi.org/10.1029/2000WR900090.

Iverson, R.M., Major, J.J., 1987. Rainfall, ground-water flow, and seasonal movement at Minor Creek landslide, northwestern California: physical interpretation of empirical relations. Geol. Soc. Am. Bull. 99, 579-594.

James, M.R., Robson, S., 2014. Mitigating systematic error in topographic models derived from UAV and ground-based image networks. Earth Surf. Process. Landf. 39, 1413-1420. https://doi.org/10.1002/esp.3609.

Keefer, D.K., 2002. Investigating landslides caused by earthquakes - a historical review. Surv. Geophys. 23, 473-510. https://doi.org/10.1023/A:1021274710840.

Lacroix, P., Berthier, E., Maquerhua, E.T., 2015. Earthquake-driven acceleration of slowmoving landslides in the Colca valley, Peru, detected from Pléiades images. Remote Sens. Environ. 165, 148-158. https://doi.org/10.1016/j.rse.2015.05.010.

Lacroix, P., Araujo, G., Hollingsworth, J., Taipe, E., 2019. Self-entrainment motion of a slow-moving landslide inferred from landsat-8 time series. J. Geophys. Res. Earth Surf. https://doi.org/10.1029/2018JF004920, 2018JF004920.

Lacroix, P., Handwerger, A.L., Bièvre, G., 2020. Life and death of slow-moving landslides. Nat. Rev. Earth Environ. 1, 404-419. https://doi.org/10.1038/s43017 020-0072-8.

Leprince, S., Barbot, S., Ayoub, F., Avouac, J.P., 2007. Automatic, precise, Orthorectification and Coregistration for satellite image correlation, Application to Ground Deformation Measurement. IEEE J. Geosci. Rem. Sens. 45, 1529-1558. https://doi.org/10.1109/TGRS.2006.888937.

Li, M., Zhang, L., Shi, X., Liao, M., Yang, M., 2019. Monitoring active motion of the Guobu landslide near the Laxiwa Hydropower Station in China by time-series pointlike targets offset tracking. Remote Sens. Environ. 221, 80-93. https://doi.org/ 10.1016/j.rse.2018.11.006.

Lissak, C., Bartsch, A., De Michele, M., Gomez, C., Maquaire, O., Raucoules, D., Roulland, T., 2020. Remote sensing for assessing landslides and associated hazards. Surv. Geophys. https://doi.org/10.1007/s10712-020-09609-1.

Mackey, B.H., Roering, J.J., 2011. Sediment yield, spatial characteristics, and the longterm evolution of active earthflows determined from airborne LiDAR and historical aerial photographs, Eel River. California. Bull. Geol. Soc. Am. 123, 1427-1447. https://doi.org/10.1130/B30306.1.

Malet, J.-P., Maquaire, O., Calais, E., 2002. The use of global positioning system techniques for the continuous monitoring of landslides: application to the SuperSauze earthflow (Alpes-de-Haute-Provence, France). Geomorph. 43, 33-54. https:// doi.org/10.1016/S0169-555X(01)00098-8.

Manconi, A., Casu, F., Ardizzone, F., Bonano, M., Cardinali, M., De Luca, C., Gueguen, E., Marchesini, I., Parise, M., Vennari, C., Lanari, R., Guzzetti, F., 2014. Brief communication: rapid mapping of landslide events: the 3 December 2013 
Montescaglioso landslide, Italy. Nat. Hazards Earth Syst. Sci. 14, 1835-1841. https://doi.org/10.5194/nhess-14-1835-2014.

Massey, C.I., Petley, D.N., McSaveney, M.J., 2013. Patterns of movement in reactivated landslides. Eng. Geol. 159, 1-19. https://doi.org/10.1016/j.enggeo.2013.03.011.

Massey, C.I., Petley, D.N., McSaveney, M.J., Archibald, G., 2016. Basal sliding and plastic deformation of a slow, reactivated landslide in New Zealand. Eng. Geol. 208, 11-28. https://doi.org/10.1016/j.enggeo.2016.04.016.

Migon, P., 2010. Mass movement and landscape evolution in weathered granite and gneiss terrains. Geol. Soc. London Eng. Geol. Spec. Publ. 23, 33-45. https://doi.org/ 10.1144/EGSP23.4.

Milillo, P., Fielding, E.J., Shulz, W.H., Delbridge, B., Burgmann, R., 2014. COSMOSkyMed spotlight interferometry over rural areas: the slumgullion landslide in Colorado, USA. IEEE J. Sel. Top. Appl. Earth Obs. Remote Sens. 7, 2919-2926. https://doi.org/10.1109/JSTARS.2014.2345664.

Moeyersons, J., Tréfois, P., Lavreau, J., Alimasi, D., Badriyo, I., Mitima, B., Mundala, M., Munganga, D.O., Nahimana, L., 2004. A geomorphological assessment of landslide origin at Bukavu, Democratic Republic of the Congo. Eng. Geol. 72, 73-87. https:// doi.org/10.1016/j.enggeo.2003.06.003.

Monsieurs, E., 2020. The Potential of Satellite Rainfall Estimates in Solving Regional Landslide Hazard Modelling in Data-Scarce Contexts. Royal Museum for Central Africa / Université de Liège.

Monsieurs, E., Jacobs, L., Michellier, C., Basimike Tchangaboba, J., Ganza, G.B., Kervyn, F., Maki Mateso, J.-C., Mugaruka Bibentyo, T., Kalikone Buzera, C., Nahimana, L., Ndayisenga, A., Nkurunziza, P., Thiery, W., Demoulin, A., Kervyn, M., Dewitte, O., 2018. Landslide inventory for hazard assessment in a data-poor context: a regional-scale approach in a tropical African environment. Landslides 15, 2195-2209. https://doi.org/10.1007/s10346-018-1008-y.

Nereson, A.L., Davila Olivera, S., Finnegan, N.J., 2018. Field and remote-sensing evidence for hydro-mechanical isolation of a long-lived earthflow in Central California. Geophys. Res. Lett. 45, 9672-9680. https://doi.org/10.1029/ 2018GL079430.

Osmanoğlu, B., Sunar, F., Wdowinski, S., Cabral-Cano, E., 2016. Time series analysis of InSAR data: methods and trends. ISPRS J. Photogramm. Remote Sens. 115, 90-102. https://doi.org/10.1016/j.isprsjprs.2015.10.003.

Oth, A., Barrière, J., d'Oreye, N., Mavonga, G., Subira, J., Mashagiro, N., Kadufu, B., Fiama, S., Celli, G., de Bigirande, J.D., Ntenge, A.J., Habonimana, L., Bakundukize, C., Kervyn, F., 2017. KivuSNet: the first dense broadband seismic network for the Kivu rift region (Western branch of east African rift). Seismol. Res. Lett. 88, 49-60. https://doi.org/10.1785/0220160147.

Pasteels, P., Villeneuve, M., De Paepe, P., Klerkx, J., 1989. Timing of the volcanism of the southern Kivu province: implications for the evolution of the western branch of the east African rift system. Earth Planet. Sci. Lett. 94, 353-363.

Petley, D.N., Carey, J.M., Ng, K.-Y., Massey, C.I., Froude, M.J., 2017. Understanding patterns of movement for slow moving landslides. In: Alexander, G., Chin, C. (Eds.) 20th Symposium of the New Zealand Geotechnical Society. New Zealand Geotechnical Society, pp. 1-11.

Raucoules, D., de Michele, M., Malet, J.P., Ulrich, P., 2013. Time-variable 3D ground displacements from high-resolution synthetic aperture radar (SAR). Application to La Valette landslide (South French Alps). Remote Sens. Environ. 139, 198-204. https://doi.org/10.1016/j.rse.2013.08.006.

Rupnik, E., Daakir, M., Pierrot-Deseilligny, M., 2017. MicMac - a free, open-source solution for photogrammetry. Open Geospatial Data, Softw. Stand 2, 14. https://doi. org/10.1186/s40965-017-0027-2.

Samsonov, S., d'Oreye, N., 2012. Multidimensional time-series analysis of ground deformation from multiple InSAR data sets applied to Virunga Volcanic Province. Geophys. J. Int. 191, 1095-1108. https://doi.org/10.1111/j.1365246X.2012.05669.x.

Samsonov, S., D’Oreye, N., 2017. Multidimensional Small Baseline Subset (MSBAS) for two-dimensional deformation analysis: case study Mexico City. Can. J. Remote. Sens. 43, 318-329. https://doi.org/10.1080/07038992.2017.1344926.

Samsonov, S., Dille, A., Dewitte, O., Kervyn, F., D’Oreye, N., 2020. Satellite interferometry for mapping surface deformation time series in one, two and three dimensions: a new method illustrated on a slow-moving landslide. Eng. Geol. 266 https://doi.org/10.1016/j.enggeo.2019.105471.
Sánchez-gámez, P., Navarro, F.J., 2017. Glacier surface velocity retrieval using D-InSAR and offset tracking techniques applied to ascending and descending passes of Sentinel-1 data for southern Ellesmere ice caps. Canadian Arctic. Remote Sens. 9, 442. https://doi.org/10.3390/rs9050442.

Scaioni, M., Longoni, L., Melillo, V., Papini, M., 2014. Remote sensing for landslide investigations: an overview of recent achievements and perspectives. Remote Sens. 6, 5909-5937. https://doi.org/10.3390/rs60x000x.

Scheffler, D., Hollstein, A., Diedrich, H., Segl, K., Hostert, P., 2017. AROSICS: An automated and robust open-source image co-registration software for multi-sensor satellite data. Remote Sens. 9. https://doi.org/10.3390/rs9070676.

Schlögel, R., Doubre, C., Malet, J.P., Masson, F., 2015. Landslide deformation monitoring with ALOS/PALSAR imagery: a D-InSAR geomorphological interpretation method. Geomorph. 231, 314-330. https://doi.org/10.1016/j.geomorph.2014.11.031.

Schulz, W.H., Kean, J.W., Wang, G., 2009a. Landslide movement in Southwest Colorado triggered by atmospheric tides. Nat. Geosci. 2, 863-866. https://doi.org/10.1038/ ngeo659.

Schulz, W.H., McKenna, J.P., Kibler, J.D., Biavati, G., 2009b. Relations between hydrology and velocity of a continuously moving landslide-evidence of porepressure feedback regulating landslide motion? Landslides 6, 181-190. https://doi. org/10.1007/s10346-009-0157-4.

Schulz, W.H., Coe, J.a., Ricci, P.P., Smoczyk, G.M., Shurtleff, B.L., Panosky, J., 2017. Landslide kinematics and their potential controls from hourly to decadal timescales: insights from integrating ground-based InSAR measurements with structural maps and long-term monitoring data. Geomorph. 285, 121-136. https://doi.org/10.1016/ j.geomorph.2017.02.011.

Sentinel Hub, 2020. Copernicus Sentinel data 2020/Sentinel Hub [WWW Document]. Sinergise Ltd.

Singleton, A., Li, Z., Hoey, T., Muller, J.P., 2014. Evaluating sub-pixel offset techniques as an alternative to D-InSAR for monitoring episodic landslide movements in vegetated terrain. Remote Sens. Environ. 147, 133-144. https://doi.org/10.1016/j. rse.2014.03.003.

Stumpf, A., Malet, J.P., Allemand, P., Ulrich, P., 2014. Surface reconstruction and landslide displacement measurements with Pléiades satellite images. ISPRS J. Photogramm. Remote Sens. 95, 1-12. https://doi.org/10.1016/j. isprsjprs.2014.05.008.

Stumpf, A., Malet, J.P., Delacourt, C., 2017. Correlation of satellite image time-series for the detection and monitoring of slow-moving landslides. Remote Sens. Environ. 189, 40-55. https://doi.org/10.1016/j.rse.2016.11.007.

Stumpf, A., Michéa, D., Malet, J.-P., 2018. Improved co-registration of Sentinel-2 and Landsat-8 imagery for earth surface motion measurements. Remote Sens. 10, 160. https://doi.org/10.3390/rs10020160.

Sun, L., Muller, J.P., 2016. Evaluation of the use of sub-pixel offset tracking techniques to monitor landslides in densely vegetated steeply sloped areas. Remote Sens. 8. https://doi.org/10.3390/rs8080659.

Sun, L., Muller, J.-P.P., Chen, J., 2017. Time series analysis of very slow landslides in the three Gorges region through small baseline SAR offset tracking. Remote Sens. 9, 1314. https://doi.org/10.3390/rs9121314.

Team, Planet, 2020. Planet Application Program Interface: In Space for Life on Earth [WWW Document]. URL. https://api.planet.com.

Thomas, M.F., 1994. Geomorphology in the Tropics: A Study of Weathering and Denudation in Low Latitudes. John Wiley \& Sons.

Turner, D., Lucieer, A., de Jong, S.M., 2015. Time series analysis of landslide dynamics using an Unmanned Aerial Vehicle (UAV). Remote Sens. 7, 1736-1757. https://doi. org $/ 10.3390 /$ rs70201736.

USGS, 2020. USGS Earthquake Hazards Program [WWW Document]. URL. https://earth quake.usgs.gov/.

Wasowski, J., Bovenga, F., 2014. Investigating landslides and unstable slopes with satellite Multi Temporal Interferometry: current issues and future perspectives. Eng. Geol. 174, 103-138. https://doi.org/10.1016/j.enggeo.2014.03.003.

Xu, Y., Lu, Z., Schulz, W.H., Kim, J., 2020. Twelve-year dynamics and rainfall thresholds for alternating creep and rapid movement of the Hooskanaden landslide from integrating InSAR, pixel offset tracking, and borehole and hydrological measurements. J. Geophys. Res. Earth Surf. https://doi.org/10.1029/ 2020JF005640. 